\title{
Transient conjugated heat transfer in thick walled pipes with axially periodic surface temperature in downstream region
}

\author{
ALI ATEŞ@ \\ Ilgin Vocational School, Selcuk University, Konya, Turkey \\ e-mail: aates@selcuk.edu.tr
}

MS received 3 August 2018; revised 20 November 2018; accepted 22 January 2019; published online 19 March 2019

\begin{abstract}
Thermal entrance region transient conjugate heat transfer is investigated involving fluid axial heat conduction for laminar pipe flows. Constant outer wall temperature boundary condition is assumed in the upstream region of a thick walled, two regional pipe. In the downstream region, the outer wall temperature is considered changing spatially in a periodical manner. The problem is solved numerically by a finite difference method. A parametric analysis is conducted in order to determine the effects of Peclet number, wall thickness ratio, wall-to-fluid thermal conductivity ratio, wall-to-fluid thermal diffusivity ratio and axial frequency on heat transfer characteristics. It is seen that, the results are highly dependent on the parameter values and the most effective ones are the Peclet number and the wall thickness ratio. It is observed that heat is transferred towards upstream due to the axial conduction in the wall and in the fluid and with increasing values for high axial frequency.
\end{abstract}

Keywords. Axially periodic temperature; transient conjugate heat transfer; laminar flow in pipes; thick walled pipe.

\section{Introduction}

Pipes with surface temperature changing periodically in axial direction is important to understand the technical aspects. Some examples may be petroleum or natural gas pipes under wavy seabeds, heat exchangers of machineries working with Stirling Cycle and cooling systems of nuclear reactors. Some investigations in literature is about sinusoidal change of interfacial heat flux in axial direction for hydrodynamically developed flows. Meanwhile, analysis of transient conjugate heat transfer is important for heat exchangers at start-up, shutdown or for any change in the operation conditions.

Transient heat transfer in pipes and channels for laminar flow has been investigated by several researchers. Some of these works considered are very thin walls in which conduction through the wall can be neglected in all directions and conditions at the outer surface can be assumed to be prevailed at the wall-fluid interface. However, in conjugated problems, the boundary conditions at interface arenot known previously and the energy equations should be solved together for both the wall and the fluid sides with the continuity of temperatures and/or heat fluxes at the interface. In some of these aforementioned problems, thermal conduction in radial direction is neglected while in some of the problems, both axial and radial wall conduction are involved [1, 2]. Nevertheless, fluid axial conduction as compared to the convection cannot be neglected in flows having low Peclet numbers and temperature profile begins to develop prior to the heating section due to the diffusion of heat towards upstream in the inverse direction of the flow. Therefore, these kinds of problems should be solved in a two-regional domain and heat transfer characteristics should be determined for both upstream and downstream regions.

Transient conjugated heat transfer problem was investigated in numerous studies in case of instant and/or periodical changes in boundary or inlet conditions. Some numerical solutions were proposed for the problem for thick walled pipes in which conduction in two directions exists [3]. A comprehensive literature survey was conducted by [2] for these problems. Wijeysundera [1] analytically investigated a steady state conjugated heat transfer problem, including axial wall conduction with convective boundary condition at the outer surface in circular pipes and rectangular channels having a finite heated part. The author reported that wall and fluid temperatures are strongly depended on the wall conduction parameter and an improvement in heat flux depending on the wall conduction and attaining higher values only for a short distance from the inlet. A steady flow problem in pipes with convective boundary condition at the outer surface was investigated with analytical methods by [4] considering the effects of fluid axial conduction. Temperature distribution and local Nusselt Numbers are given for different Biot Numbers for both upstream and downstream regions. Lee and Hwang [5] solved a problem with a parabolic velocity profile in the 
thermal entrance region of a circular pipe by using the finite elements method. Authors stated that numerical solution gives more realistic values, especially where analytical solution yielded unrealistic results. Ates [6] and Darici [7] investigated conjugated heat transfer in thick walled pipes. In the former, a constant heat flux boundary condition is defined at the outer surface of the pipe, while in the latter it is investigated a case in which velocity and temperature develop simultaneously in a single regional pipe.

Some works in the literature focused on a special case of conjugate heat transfer problem. They dealt with axially sinusoidal change of interfacial heat flux in steady and hydrodynamically developed flows. Some numerical solutions have been developed to the problem for thick walled pipes where two-dimensional wall conduction is taken into consideration. Problems having axially changing periodical boundary condition were studied by [8-25] under various circumstances.

Hsu [8] investigated heat and mass transfer numerically for laminar flow in a problem with axially changing periodical wall heat flux. The problem is first solved for uniform heat flux and then for sinusoidal changing wall heat flux and it is stated that the asymptotic expressions obtained are satisfactorily accurate. Patankar et al [9] reported a method by which universal results can be generated in the fully developed region for the periodical flows. Li and Kakac [10] theoretically investigated transient conjugated heat transfer problem for forced laminar flow inside a rectangular channel at different boundary conditions and for inlet temperature changing periodically with time. The authors obtained analytical expressions by extending generalized integral transform technique. In another study, which was published by Quaresma and Cotta [11], an exact analytical solution is presented by using integral transforms. They obtained temperature distribution and Nusselt Numbers in the thermal entrance region of pipes with variable wall heat flux in the axial direction. A case in which thermal boundary condition changes instantly in axial direction more than one time is investigated by [12]. The author solved the conjugated heat transfer problem for turbulent channel flow numerically by using the $k-\varepsilon$ model improved for low Reynolds Number turbulent flows that was proposed by [13]. Convective boundary condition is considered and the effects of wall conduction and wall heat capacity are taken into consideration in the solution. It is reported that the conjugated heat transfer is significantly affected from conduction in the wall, though the flow is turbulent. Another analytical study in which ambient temperature is changing periodically for hydrodynnamically developed laminar flow inside a thin walled pipe was investigated by [14]. The periodical thermal boundary condition changes in a sinusoidal manner. Later, Barletta and Rossi di Schio [15] studied a similar problem including the effects of viscous dissipation. The problem is defined in the thermally developing region and axial heat conduction in the fluid is neglected. Authors reported that the viscous dissipation can be effective when the average value of heat flux changing sinusoidally is in decrease in a period. Barletta and Rossi di Schio [16] and Barletta et al [17] included fluid axial conduction along with the axially periodical changing interfacial heat flux boundary condition and compared with [15] in which fluid axial conduction was neglected. It is stated that amplitudes of the sinusoidal waves become smaller in cases of low Peclet numbers. Axial conduction in fluid zone cannot be neglected here. The amplitudes of temperature is also decreasing with distance from wall to axis of the channel. Zniber et al [18] numerically investigated heat transfer in a two-dimensional channel in case of a periodically changing sinusoidal heat flux in a Magneto-Hydrodynamic laminar flow. Viscous and Joule dissipations are neglected in the study. Temperature distribution, local and average Nusselt numbers were obtained by using the linear operators technique and axial heat conduction is taken into consideration. It was determined that the local Nusselt number increases as the Hartmann number increases [19]. Barletta et al [20] again investigated heat transfer in pipes used in petroleum transport in open seas. This is a certain case of periodically changing thermal boundary condition. Conti et al [21] investigated a conjugated heat transfer problem in micro-channels for the cases of heat flux changing both periodically and instantly. The investigated micro-channel has a rectangular cross-section and it was stated that it is used for cooling of electronics mostly. It is expressed that narrow channels are more affected from heat flux and the most effective parameter for the widest channel dimension in their work is the velocity parameter. Recently, Altun et al [22] worked on a transient conjugated heat transfer problem in thick walled pipes, under time-wise periodically changing outer wall temperature boundary condition. Similar problems under different boundary conditions were taken into consideration by [23-25]. The general findings from the above works can be summarized as given below. The quasi-steady analysis for transient conjugated heat transfer problems can lead to serious errors at the initial stages. The time required to reach to the steady state conditions is longer for lower Peclet number, Biot number and thermal diffusion ratio and for higher values of wall to fluid thermal conductivity ratio and wall thickness ratio. The thickness of the pipe wall is the most effective parameter in conjugated heat transfer problems. Sometimes heat transfer from fluid to the wall can be seen in conjugate heat transfer problems where higher rates of heat transfer from wall to the ambient is seen. It is also seen that the velocity profile has significant effect on the results in transient conjugated heat transfer problems in the thermal entrance region.

In this work, heat transfer in a thick walled pipe for laminar flow for which fluid axial conduction is important 
has been investigated numerically. In other words, thermal entrance region transient conjugated heat transfer with laminar flow, in a thick walled two-regional pipe is solved numerically including the fluid axial conduction. Constant surface temperature boundary condition is assumed in the upstream region and outer surface temperature of the wall is changing in the axial direction periodically in the downstream region when the pipe is divided into two semiinfinite regions. When the pipe is divided, the upstream part makes the flow hydrodynamical. So a unique boundary condition or an instant change in the downstream region in terms of heat transfer lead to transient phenomena in the thermal entry length of the downstream region. The two novel aspects of the work are axially periodic change of the wall outer surface temperature and fluid axial conduction. The wall thickness ratio and the Peclet Number are found to be the most effective parameters for the problem. It is seen that heat transfer occurs towards upstream region due to the wall and fluid axial conduction and heat transfer towards this direction is more effective for higher values of frequency. The reason is concluded to be the increasing effect of fluid axial conduction compared to the wall axial conduction.

\section{Definition of the problem}

The schematic diagram and the coordinate system of the problem are given in figure 1. The flow pipe has two regions and both regions are semi-infinite. The fluid enters the pipe at a uniform temperature $T_{o}$ at the far side of the upstream $(x=-\infty)$ and this temperature is also the initial temperature of the whole system. The flow is assumed to be developed in the upstream region hydrodynamically. At the beginning of time, $(t=0)$, the downstream region of the pipe is started to be heated with a surface temperature which changes periodically in the axial direction. All physical properties of the fluid and the wall are assumed to be constant and viscous dissipation is neglected. Changes in the physical properties of matter depending on the temperature can be ignored for small amounts of $\Delta T$. This condition is considered for this study. Peclet number, on the other hand, changes between 2 and 20. Since flow velocity is very low in this interval, viscous dissipation can be neglected.

The problem defined above can be formulated in nondimensional form as follows.

Differential equation in the wall side;

$$
\frac{1}{\alpha_{w f}} \frac{\partial T_{w}^{*}}{\partial t^{*}}=\frac{1}{r^{*}} \frac{\partial}{\partial r^{*}}\left(r^{*} \frac{\partial T_{w}^{*}}{\partial r^{*}}\right)+\frac{1}{P e^{2}} \frac{\partial^{2} T_{w}^{*}}{\partial x^{*^{2}}}
$$

Initial and boundary conditions;

$$
\begin{gathered}
T_{w}^{*}=0 \text { for } t^{*}=0 \\
T_{w}^{*}=0 \text { for } x^{*}=-\infty \\
T_{w}^{*}\left(x^{*}, r^{*}\right)=T_{w}^{*}\left(x^{*}+\frac{2 \pi}{B}, r^{*}\right) \text { for } x^{*}=+\infty
\end{gathered}
$$

Equation (1d) is a boundary condition that is also used as a criterion for determining the thermal development. It shows that, for a given $r^{*}, T_{w}^{*}$ values for $x^{*}$ positions at the same wave phase are equal.

$$
\begin{gathered}
T_{w}^{*}=0 \text { for } r^{*}=1+d^{*} \text { and } x^{*}<0 \\
T_{w}^{*}=\left[1-\operatorname{Cos}\left(B x^{*}\right)\right] \text { for } r^{*}=1+d^{*} \text { and } x^{*} \geq 0 \\
T_{w}^{*}=T_{f}^{*} \text { and also } \frac{\partial T_{w}^{*}}{\partial r^{*}}=\frac{1}{k_{w f}} \frac{\partial T_{f}^{*}}{\partial r^{*}} \text { for } r^{*}=1 .
\end{gathered}
$$

Differential equation in the fluid side;

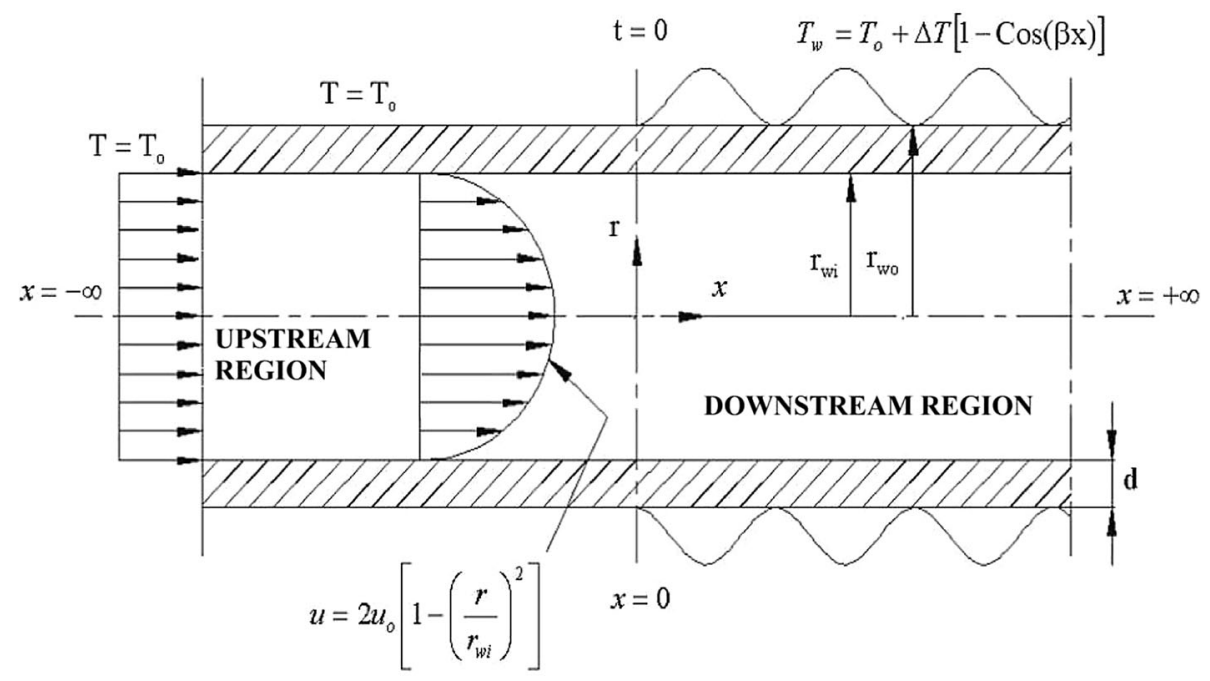

Figure 1. The schematic diagram and the coordinate system of the problem. 


$$
\frac{\partial T_{f}^{*}}{\partial t^{*}}+\left(1-r^{*^{2}}\right) \frac{\partial T_{f}^{*}}{\partial x^{*}}=\frac{1}{r^{*}} \frac{\partial}{\partial r^{*}}\left(r^{*} \frac{\partial T_{f}^{*}}{\partial r^{*}}\right)+\frac{1}{P e^{2}} \frac{\partial^{2} T_{f}^{*}}{\partial x^{*^{2}}}
$$

Initial and boundary conditions;

$$
\begin{gathered}
T_{f}^{*}=0 \text { for } t^{*}=0 \\
T_{f}^{*}=0 \text { for } x^{*}=-\infty \\
T_{f}^{*}\left(x^{*}, r^{*}\right)=T_{f}^{*}\left(x^{*}+\frac{2 \pi}{B}, r^{*}\right) \text { for } x^{*}=+\infty \\
T_{f}^{*}=T_{w}^{*} \text { and also } \frac{\partial T_{f}^{*}}{\partial r^{*}}=k_{w f} \frac{\partial T_{w}^{*}}{\partial r^{*}} \text { for } r^{*}=1 \\
\frac{\partial T_{f}^{*}}{\partial r^{*}}=0 \text { for } r^{*}=0 \text { (at the pipe axis) }
\end{gathered}
$$

The nondimensional parameters are defined as follows.

$$
\begin{gathered}
T_{w, \text { max }}=T_{0}+\Delta T, T^{*}=\frac{T-T_{0}}{T_{w, \max }-T_{0}}=\frac{T-T_{0}}{\Delta T}, \\
x^{*}=\frac{x}{r_{w i} P e} \equiv \frac{2}{G z}, r^{*}=\frac{r}{r_{w i}}, d^{*}=\frac{d}{r_{w i}}, \\
k_{w f}=\frac{k_{w}}{k_{f}}, \alpha_{w f}=\frac{\alpha_{w}}{\alpha_{f}} t^{*}=\frac{t \alpha_{f}}{r_{w i}^{2}} \equiv F o, \\
P e=\operatorname{Re} . \operatorname{Pr}=\frac{2 u_{0} r_{w i} \rho_{f} c_{f}}{k_{f}}, B=P e \beta r_{w i}
\end{gathered}
$$

An important aim of this work is to see the effects of fluid axial conduction. Higher frequency means more frequent periodical temperature oscillations in unit length and hence it means that the effect of average temperature is more. Accordingly, heat transfer towards upstream region is more intensive. Fluid axial conduction is more effective for lower Pe numbers. Common effects of the two different parameters are combined in the dimensionless frequency expression.

The interfacial heat flux and the bulk temperature can be expressed as:

$$
\begin{gathered}
T_{b}^{*}=4 \int_{0}^{1} r^{*}\left(1-r^{*^{2}}\right) T_{f}^{*} d r^{*} \\
q_{w i}^{*}=-\left(\frac{\partial T_{f}^{*}}{\partial r^{*}}\right)_{r^{*}=1}
\end{gathered}
$$

\section{Solution methodology}

The systems of equations (1a)-(1h) and (2a)-(2a) are solved simultaneously by numerical finite-difference approach. The conductive terms are discretized by centraldifference schemes and convective terms in the energy differential equation for the fluid side by an exact method defined in [26]. This method of discretization is a twodimensional version of the "exact or exponential scheme" defined by Patankar [27]. For the transient terms in the equations, a fully implicit formulation in time is applied to assure stability in solutions. The temperature distribution in the grid system was determined by using Gauss-Seidel iteration method. The following discretization equation is obtained for an interior (non-boundary) nodal point $(i, j)$ in the wall and in the fluid side:

$$
\begin{aligned}
a_{i, j} T_{i, j}^{*}= & a_{i+1, j} T_{i+1, j}^{*}+a_{i-1, j} T_{i-1, j}^{*}+a_{i, j+1} T_{i, j+1}^{*}+a_{i, j-1} T_{i, j-1}^{*} \\
& +a_{i, j}^{0} T_{i, j}^{* 0}
\end{aligned}
$$

where in the fluid side

$$
\begin{gathered}
a_{i+1, j}=\left(r_{j}^{*}-r_{j}^{* 3}\right) \frac{\left(\Delta r^{*}\right)_{j}}{\exp \left[P e^{2}\left(1-r_{j}^{* 2}\right)\left(\delta x^{*}\right)_{i+1}\right]-1}, \\
a_{i-1, j}=\left(r_{j}^{*}-r_{j}^{* 3}\right) \frac{\exp \left[P e^{2}\left(1-r_{j}^{* 2}\right)\left(\delta x^{*}\right)_{i-1}\right]\left(\Delta r^{*}\right)_{j}}{\exp \left[P e^{2}\left(1-r_{j}^{* 2}\right)\left(\delta x^{*}\right)_{i-1}\right]-1} \\
a_{i, j}^{0}=\frac{r_{j}^{*}\left(\Delta x^{*}\right)_{i}\left(\Delta r^{*}\right)_{j}}{\Delta t^{*}}
\end{gathered}
$$

in the wall side

$$
\begin{aligned}
& a_{i+1, j}=\frac{r_{j}^{*}}{P e^{2}} \frac{\left(\Delta r^{*}\right)_{j}}{\left(\delta x^{*}\right)_{i+1}}, \\
& a_{i-1, j}=\frac{r_{j}^{*}}{P e^{2}} \frac{\left(\Delta r^{*}\right)_{j}}{\left(\delta x^{*}\right)_{i-1}}, \\
& a_{i, j}^{0}=\frac{r_{j}^{*}}{\alpha_{w f}} \frac{\left(\Delta x^{*}\right)_{i}\left(\Delta r^{*}\right)_{j}}{\Delta t^{*}},
\end{aligned}
$$

and in both sides

$$
\begin{gathered}
a_{i, j+1}=\frac{r_{j+1}^{*}\left(\Delta x^{*}\right)_{i}}{\left(\delta r^{*}\right)_{j+1}}, \\
a_{i, j-1}=\frac{r_{j-1}^{*}\left(\Delta x^{*}\right)_{i}}{\left(\delta r^{*}\right)_{j-1}}, \\
a_{i, j}=a_{i+1, j}+a_{i-1, j}+a_{i, j+1}+a_{i, j-1}+a_{i, j}^{0},
\end{gathered}
$$

The finite-difference formulation used in the discretization of the differential equations and the boundary conditions had been used in some previous works; $[3,22,26,28-32]$ proved to give fast and reliable results in heat transfer problems for thermally developing laminar pipe flows, especially when axial fluid conduction is important, i.e., for low Peclet number flows. 
Due to axial symmetry, the grid system is bounded between the outer surface and the axis of the pipe, while the boundaries in the axial direction is guessed by the results of some trail runs with coarse grid systems as to satisfy the conditions at these boundaries. The grids are contracted radially near the interface in both sides. The axial step size is taken to be 0.04 for both upstream and downstream regions. After successive grid refinements, the optimum number for the grid system is found to be $24 \times 280$ in order to minimize the solution time and maximize the sensitivity. A uniform time step which is 0.005 used in the solutions.

Furthermore, to verify that the solutions are grid independent, results were assessed based on the generalized Richardson extrapolation and grid converge index (GCI) suggested by Roache [33]. Sample solutions were made by using coarse and fine grids assuming the selected grid system as medium. A second order method is used in GCI analysis by taking the grid refinement ratio which is the ratio of distances between grid points of the current grid and previous grid as 2.0 [33] and therefore the grid sizes are doubled in coarse and halved in fine grid systems in both axial and radial coordinates. The quantities of interest for comparison are the rms (root mean square) values of interfacial heat flux, $q_{w i}^{*}$, and the fluid bulk temperature, $T_{b}^{*}$.

The rms expression used for this purpose is:

$$
\varphi_{r m s}=\sqrt{\frac{1}{n} \sum_{i=1}^{n} \varphi_{i}^{2}}
$$

The expression for the GCI is as follows:

$$
G C I_{f}=F_{s}\left|\frac{\varepsilon_{23}}{1-r^{p}}\right| \text { and } G C I_{c}=F_{s}\left|\frac{r^{p} \varepsilon_{12}}{1-r^{p}}\right|
$$

The $F_{s}$ in this equation is "factor of safety" and it is taken 3 for two-dimensional grid system. $\varepsilon$ is the relative error and it is calculated with the following formula:

$$
\varepsilon=\left|\frac{\varphi_{2}-\varphi_{1}}{\varphi_{1}}\right| \times 100
$$

$r$ is the distance between grid points and known as the refinement factor. It can be calculated as follows:

$$
r=\frac{h_{2}}{h_{1}}=\frac{h_{3}}{h_{2}}
$$

$r$ is taken as two in this analysis. $p$ on the other hand is found by;

$$
p=\frac{\ln \left(\frac{\varepsilon_{23}}{\varepsilon_{12}}\right)}{\ln (r)}
$$

The values calculated by using the above equations are given in tables 1 and 2 .

It is clearly seen from the above results that the solutions can be assumed as independent from the grid after $24 \times 280$

\begin{tabular}{|c|c|c|c|c|c|c|}
\hline \multirow{2}{*}{ Grid } & \multicolumn{2}{|c|}{$\varepsilon(\%)$} & \multicolumn{2}{|c|}{ GCI (\%) } & \multicolumn{2}{|c|}{$p$} \\
\hline & in $Q_{w i}^{*}$ & in $T_{b}^{*}$ & $\begin{array}{l}\text { for } \\
Q_{w i}^{*}\end{array}$ & for $T_{b}^{*}$ & $\begin{array}{l}\text { for } \\
Q_{w i}^{*}\end{array}$ & $\begin{array}{l}\text { for } \\
T_{b}^{*}\end{array}$ \\
\hline $\begin{array}{l}\text { Coarse- } \\
\text { Medium }\end{array}$ & 0.0667 & 0.7900 & 0.3715 & 3.1600 & 1.117 & 2.3 \\
\hline $\begin{array}{l}\text { Medium- } \\
\text { Fine }\end{array}$ & 0.0308 & 0.1600 & 0.0790 & 0.1223 & & \\
\hline
\end{tabular}
nodes.
Table 1. General solution values.

\begin{tabular}{lccc}
\hline & & \multicolumn{2}{c}{$\varphi_{r m s}$} \\
\cline { 3 - 4 } Grid & Subdivision & $Q_{w i}^{*}$ & $T_{b}^{*}$ \\
\hline Coarse & $12 \times 140$ & 0.1440 & 1.1670 \\
Medium & $24 \times 280$ & 0.1543 & 0.9321 \\
Fine & $48 \times 560$ & 0.1592 & 1.1200 \\
\hline
\end{tabular}

Table 2. Grid converge measures for all grid schemes.

Researches revealed that, during iterations starting from the boundary regions where temperatures or heat fluxes are given and continuing towards inner parts and streamwise direction for convection problems accelerate the solution [27]. Therefore, the nodes were being scanned starting from the outer surface towards the axis of the pipe and swept streamwise during calculations. Consecutive solution procedure was applied at wall-fluid interface by using Patankar's [27] harmonic mean approach in order to control instant changes in physical properties at the interface.

The limiting value for residuals during calculations was chosen as $10^{-7}$ and the iterations were continued until the highest value of the residuals of the governing equations for the nodes at a time step is smaller than this value. The system was assumed to be reached steady state when the iteration number is one for a time step and it means that Eq. (1d) is satisfied; so the iterations were stopped.

Generally, the solutions were converged after about 11000-14000 iterations, despite the fact that iteration and time step number depend on the values of the parameters.

\section{Results and discussion}

The problem handled depended on five dimensionless parameters. These are; Peclet Number $P e$, wall-thickness ratio $d^{*}$, wall-to-fluid thermal conductivity ratio $k_{w f}$, wallto-fluid thermal diffusivity ratio, $\alpha_{w f}$, and the dimensionless frequency, $B$. Solutions are realized for different combinations of values of these parameters; $P e=2,5$, and $20 ; d^{*}=0.02,0.1$ and $0.3 ; k_{w f}=0.1,1,10,100$ and $1000 ; \alpha_{w f}=0.1,1,10,100$ and $1000 ; B=1,6,15,60$, 90, 240 and 600. Here, values of $B$ and the other 


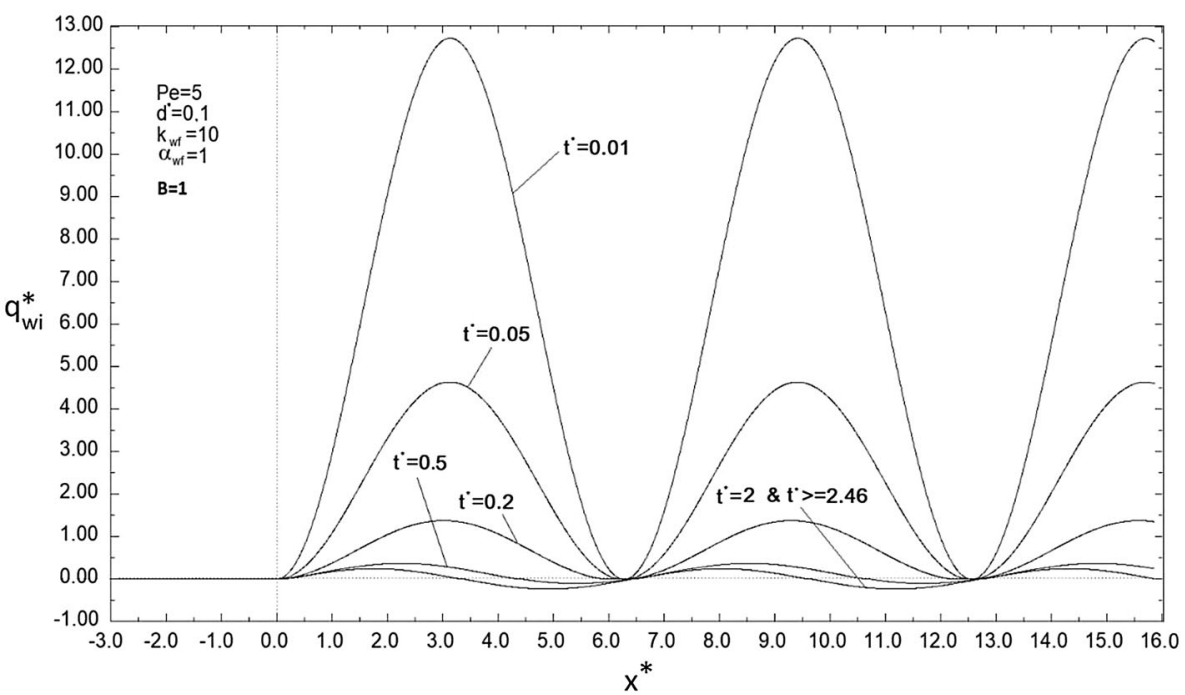

Figure 2. Transient axial distribution of interfacial heat flux $(B=1)$.

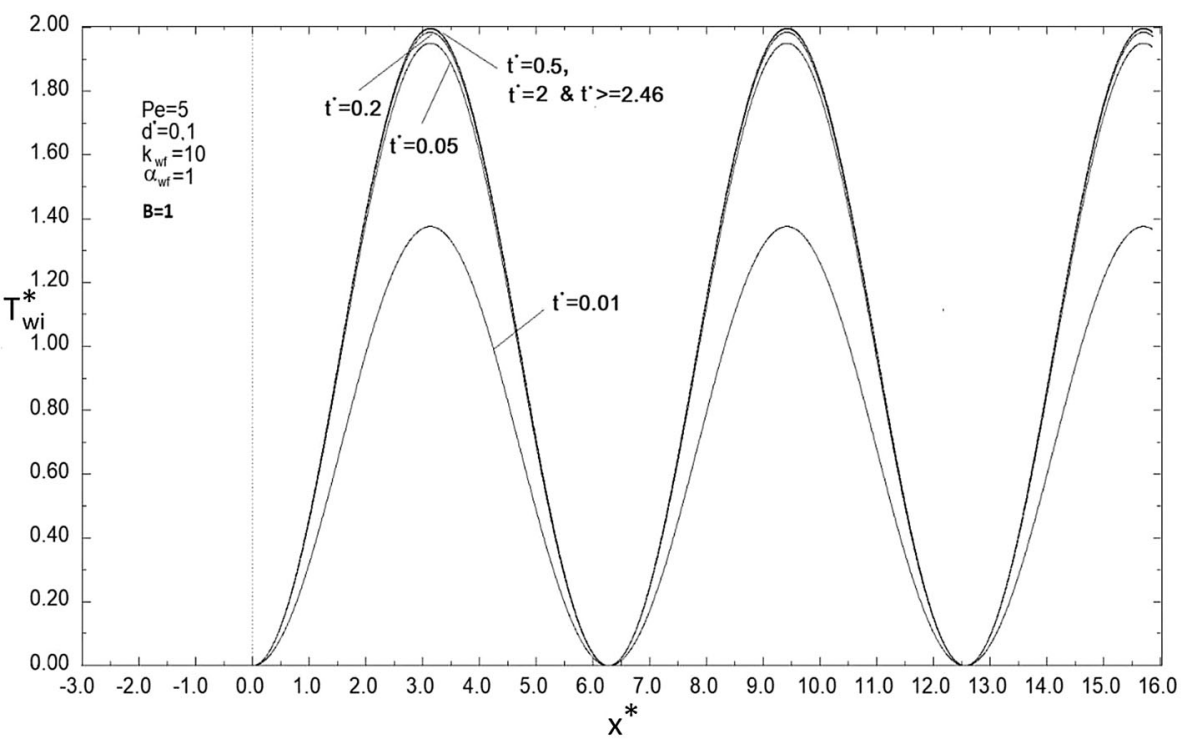

Figure 3. Transient axial distribution of interface temperature $(B=1)$.

parameters were chosen such that the values can be seen in practical engineering applications and the prescribed conditions can have a significant level (such as wall and fluid axial conduction).

Results are presented in terms of axial variation of interfacial heat flux $\left(q_{w i}\right)$ instead of local Nusselt number as per recommendation of Faghri and Sparrow [34], and Schutte et al [3]. Additionally, axial variation of interfacial $\left(T_{w i}\right)$ and fluid bulk temperature $\left(T_{b}\right)$ are also presented. The way of presenting results is a convention that is accepted in the literature $[2,3,6,7,22,26,28-32,34]$. This is due to the fact that Nusselt number contains three unknown parameters in its definition $\left(q_{w i}, T_{w i}, T_{b}\right)$ and expressing results with local Nusselt number means expressing combined effects of those parameters. This time, distinguishing their individual effects is not possible. In order to assess and evaluate the combined effect of the parameters, figures of each parameter are commented together in the following.

The axial variations of interfacial heat flux at different time instants are presented in figure 2 for $B=1$ and for a combination of some average parameter values, $P e=5$, $d^{*}=0.1, k_{w f}=10$ and $\alpha_{w f}=1$. The axial variation of interfacial and fluid bulk temperatures at different time instants for the same parameter values and for $B=1$, are given in figures 3 and 4, respectively. 


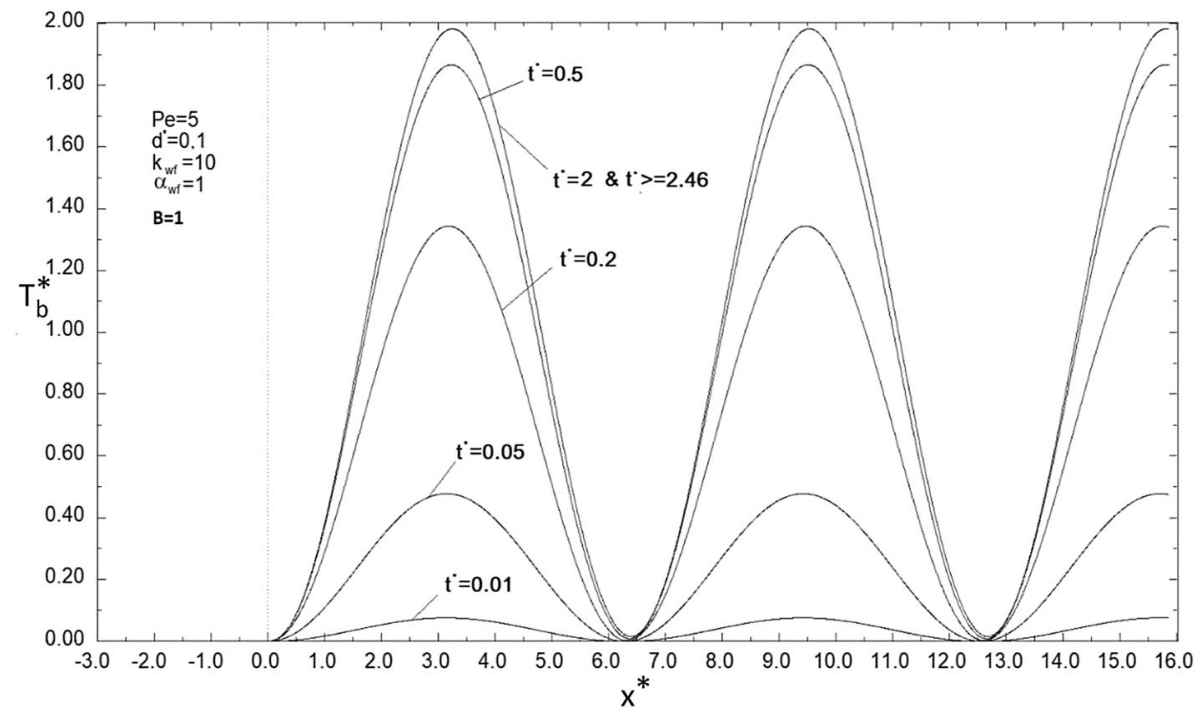

Figure 4. Transient axial distribution of bulk fluid temperature $(B=1)$.

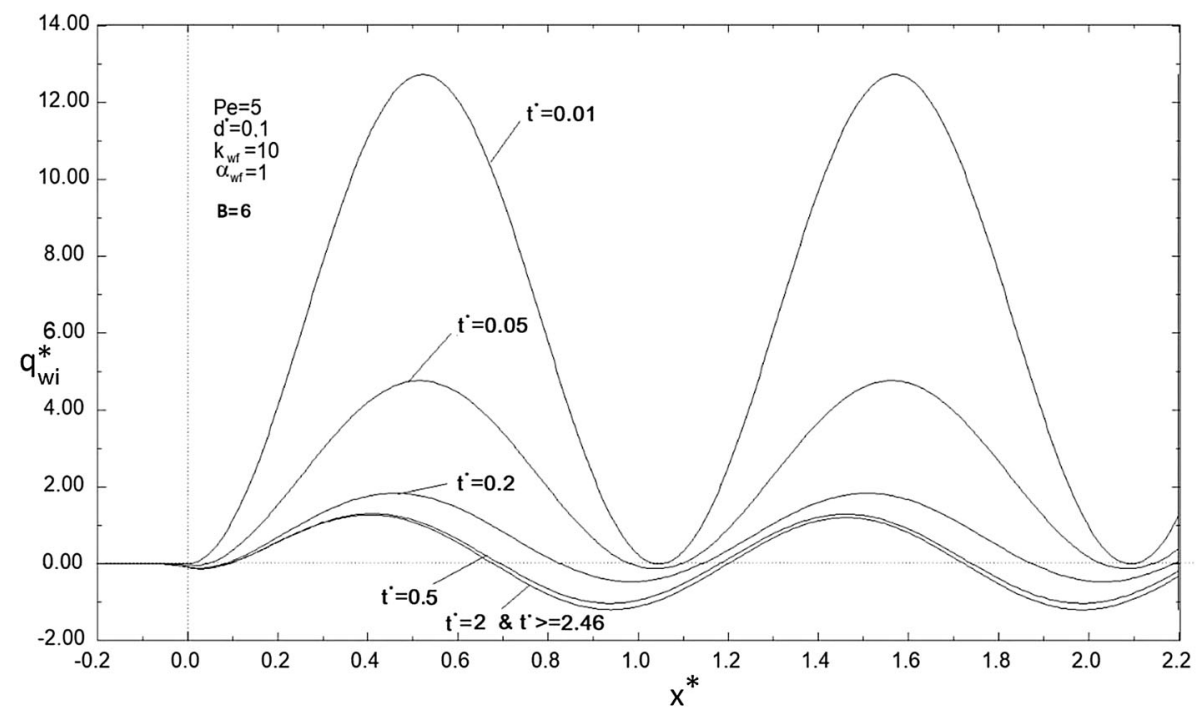

Figure 5. Transient axial distribution of interfacial heat flux $(B=6)$.

The first outcome to be inferred from the analysis of these figures together is that, the variation of interfacial temperature, fluid bulk temperature and heat flux curves varies periodically with the axial position in accordance with the variation of the downstream outer surface temperature. This periodicity is seen both in the thermal entry length and in the fully developed region starting from the beginning of time till the steady state. Thermal entry length ends with the initiation of the second period (about $x=7.5$ ) since the period is sufficiently high for this frequency.

From figures, it is seen that there seems no preheating in the upstream region. Since the outer surface temperature of the wall is held constant at $T_{0}$ in the upstream region, heat transferred towards upstream is easily lost to the environment before it reaches to the interface. No change is also seen in the interface and fluid bulk temperatures in the upstream region for the same reason.

The amplitude of heat flux decreases asymptotically with time. In addition, negative heat flux is visible for late time steps and it repeats in periodic locations. Also it is seen that, the frequency of interfacial heat flux has increased (doubled) compared to applied frequency of temperature boundary condition $(\mathrm{B}=1)$ because of this. Of course this is only visible for interfacial heat flux and not for temperature plots. This condition means that wave 


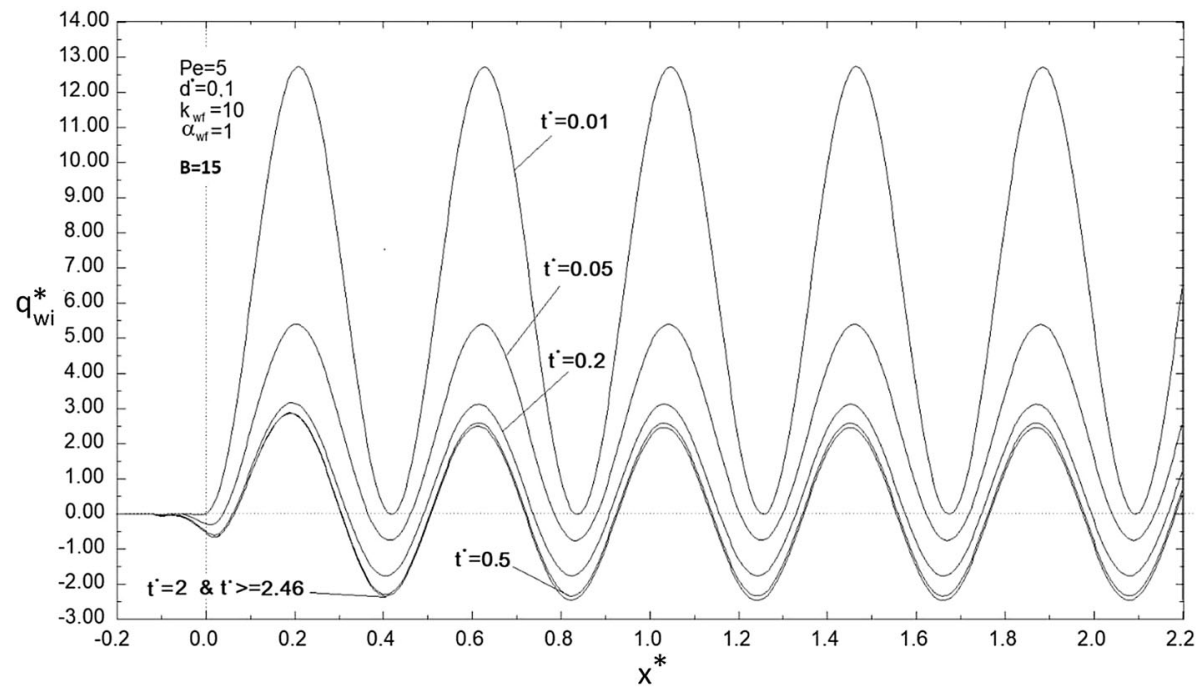

Figure 6. Transient axial distribution of interfacial heat flux $(B=15)$.

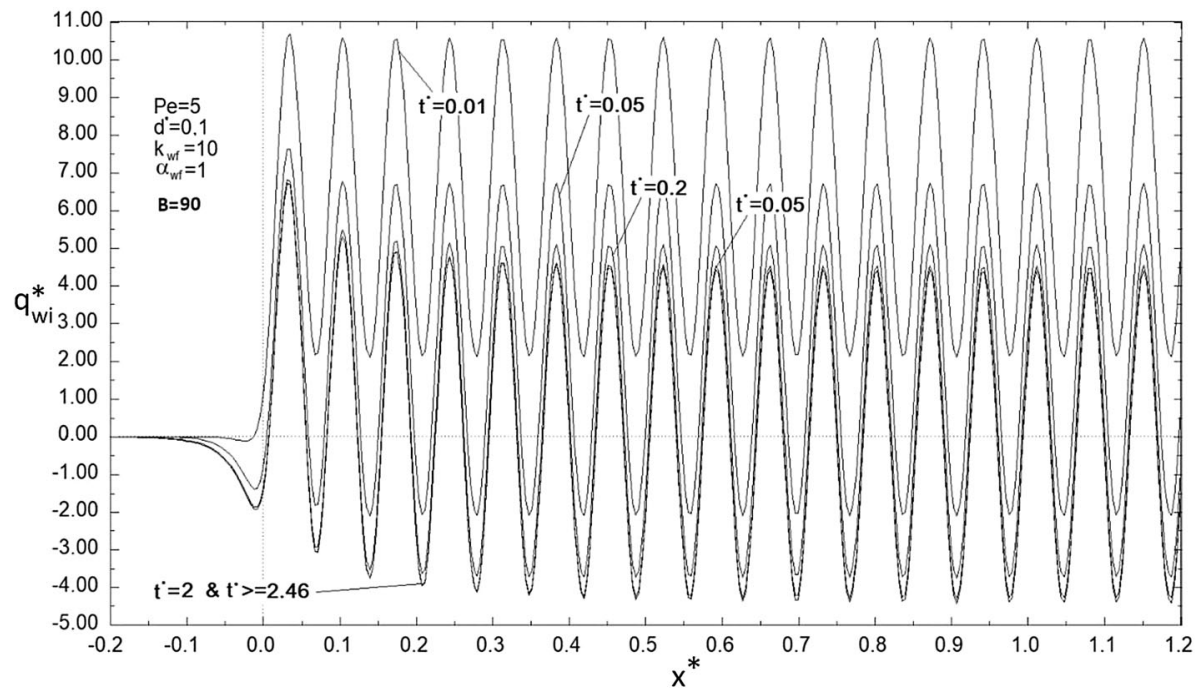

Figure 7. Transient axial distribution of interfacial heat flux $(\mathrm{B}=90)$.

length spreads to a bigger length in $+x$ direction. This means that more time is left for interface heat transfer when fluid is flowing in the pipe. Therefore, $\Delta T$ temperature difference becomes smaller due to heat transfer in this time period. The direction of the heat transfer changes between positive and negative directions for increasing time steps in the effect of fluid axial conduction. Because, a heat transfer towards upstream is realized due to the lower temperature in upstream. This leads to increasing temperature in upstream region and heat is started to be transferred from fluid to wall. It can be said that fluid axial conduction is dominant and determines the curve characteristics of heat flux for heat transfer from fluid to wall.
In the downstream region, interface temperature values increase relatively faster comparing to fluid temperature values due to rapid wall conduction at initial times. Accordingly interfacial heat flux values are high. As time progresses, values of heat flux and amplitudes of heat flux decrease. This is because of decreasing temperature difference between fluid and interface temperatures due to increasing effect of heat transfer in fluid domain. Interface temperatures are higher in the increasing part of a period and therefore positive heat flux values are realized. The higher bulk temperature values than the interface temperatures result negative heat flux during the temperature decrease part. Actually, as it continues towards $+\mathrm{x}$ direction in a period for late time steps, a phase shift occurs 


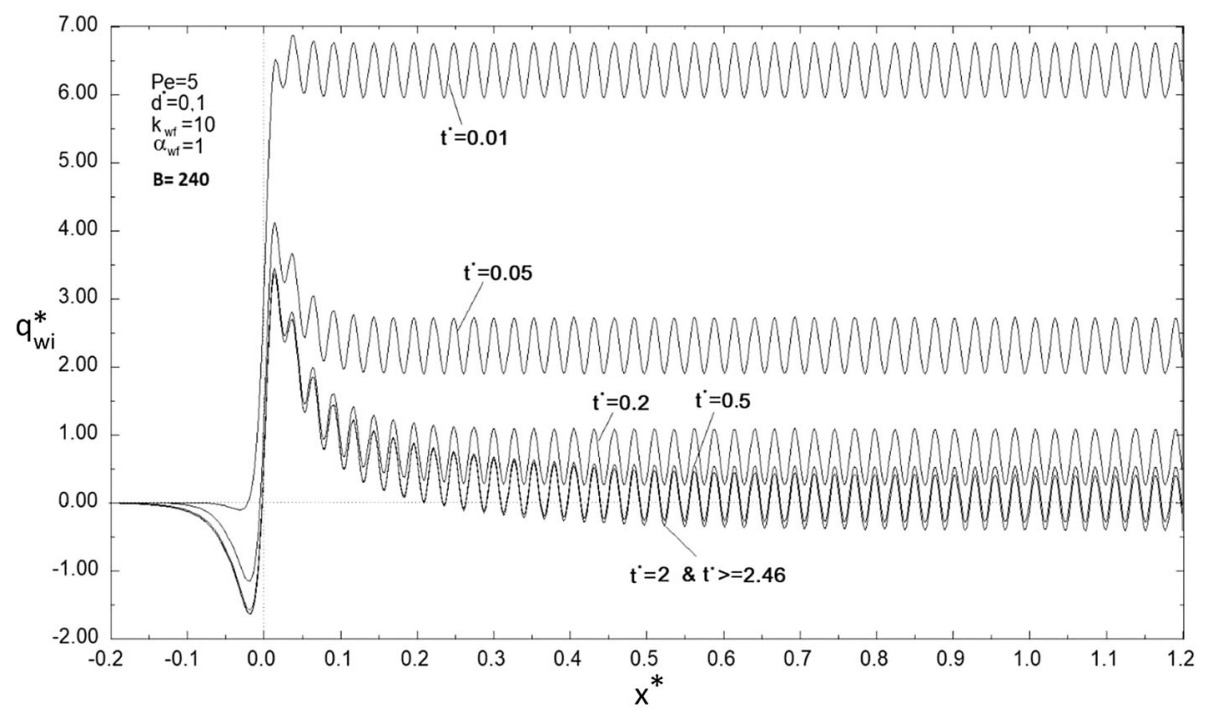

Figure 8. Transient axial distribution of interfacial heat flux $(B=240)$.

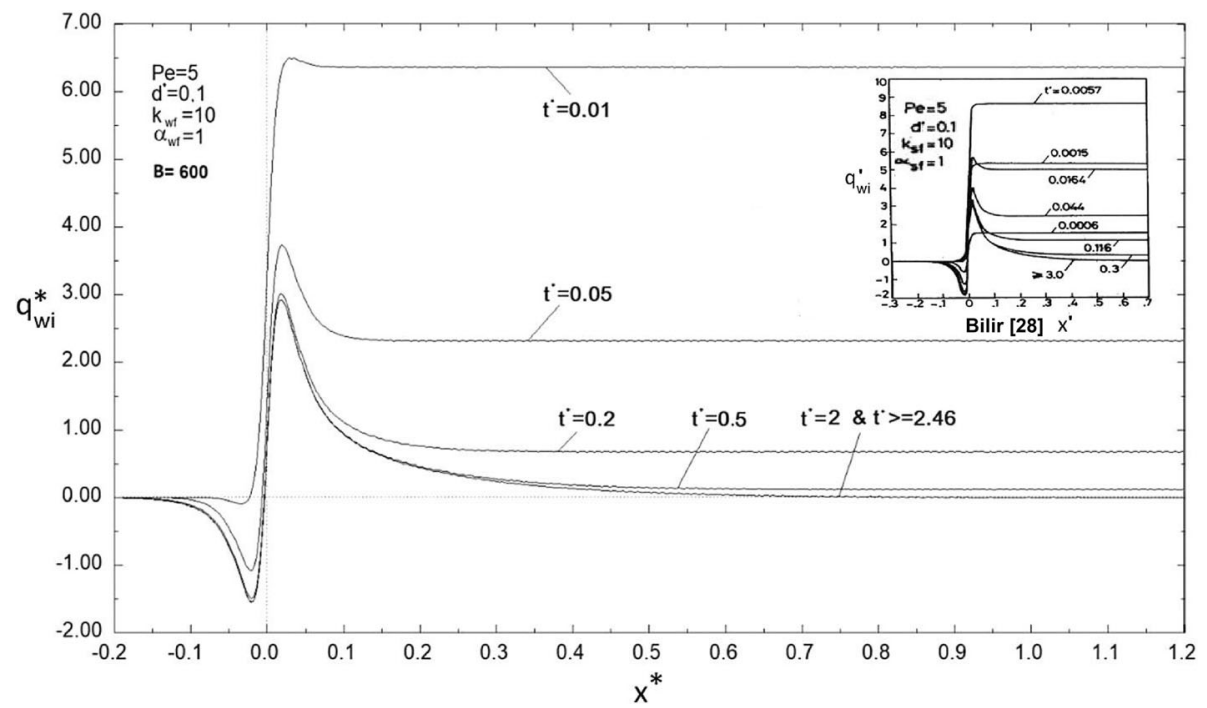

Figure 9. Transient axial distribution of interfacial heat flux $(B=600)$.

between the wave of interface temperature and fluid bulk temperature because of the heat transfer rate. Although the fluid bulk temperatures are lower for the same phase, shifting phase of the fluid bulk temperature makes some values stay above the interface temperature.

In the fully developed region, the average of heat flux values in steady state is zero and the amplitude is 0.25 and, as expected, the net heat transfer to fluid from wall becomes zero. Both interface and fluid bulk temperatures have an average value of 1.0 during the steady periodical regime in the fully developed region. The amplitude of the interface temperature is 1.0 as it is for the outer surface temperature, however fluid bulk temperature has an amplitude of about 0.98 .

The results presented so far are given for a relatively small frequency. Figures 5 to 9 show the variation of interfacial heat flux; for different times for some higher frequency values, $B=6,15,90,240$ and 600 again with the same average parameter values given previously. The results for values of $B$ lower than 1 yield completely the same trend of variation in heat transfer characteristics with $B=1$. Therefore, results for $B$ having smaller values than 1 are not given here. Similar variation trend is also seen for frequency values until $B=6$. Heat transfer is shown from downstream region towards the upstream region with the effect of wall and fluid axial conduction and this heat transfer causes preheating of fluid prior to the heated downstream region of the pipe. For higher values of $\mathrm{B}$, the decreasing period length increases the average wall temperature in the downstream region near the beginning of the heating section. The magnitude of backward heat transfer to 


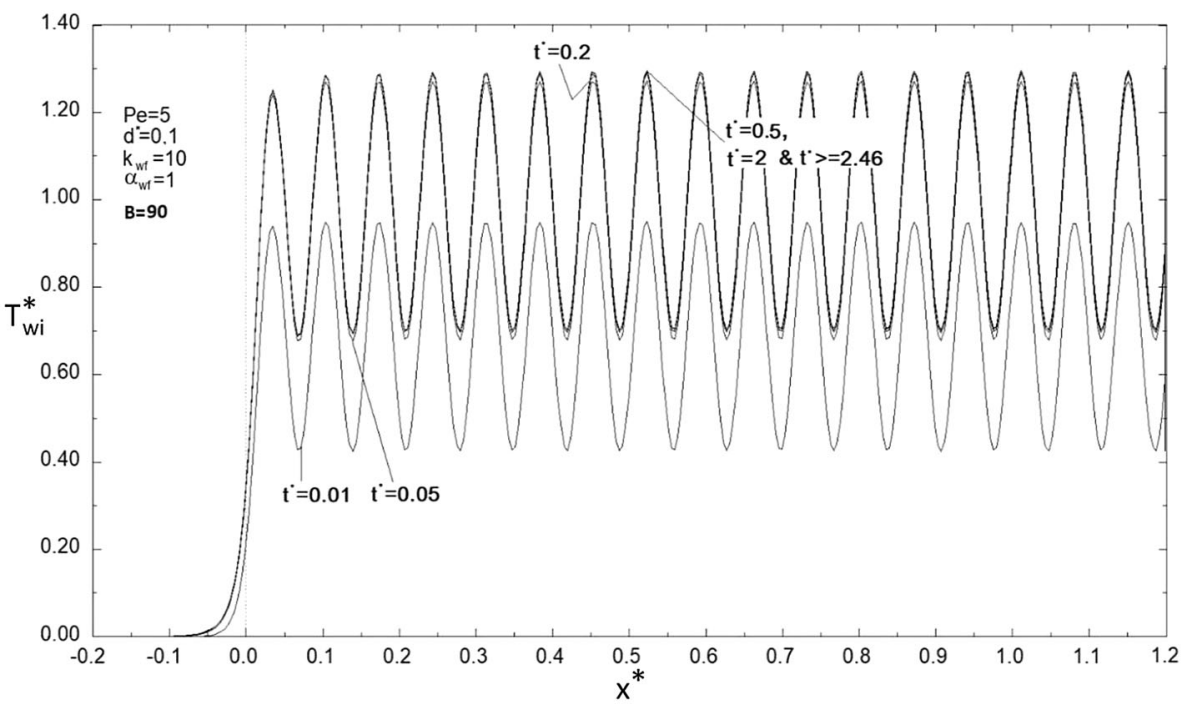

Figure 10. Transient axial distribution of interface temperature $(B=90)$.

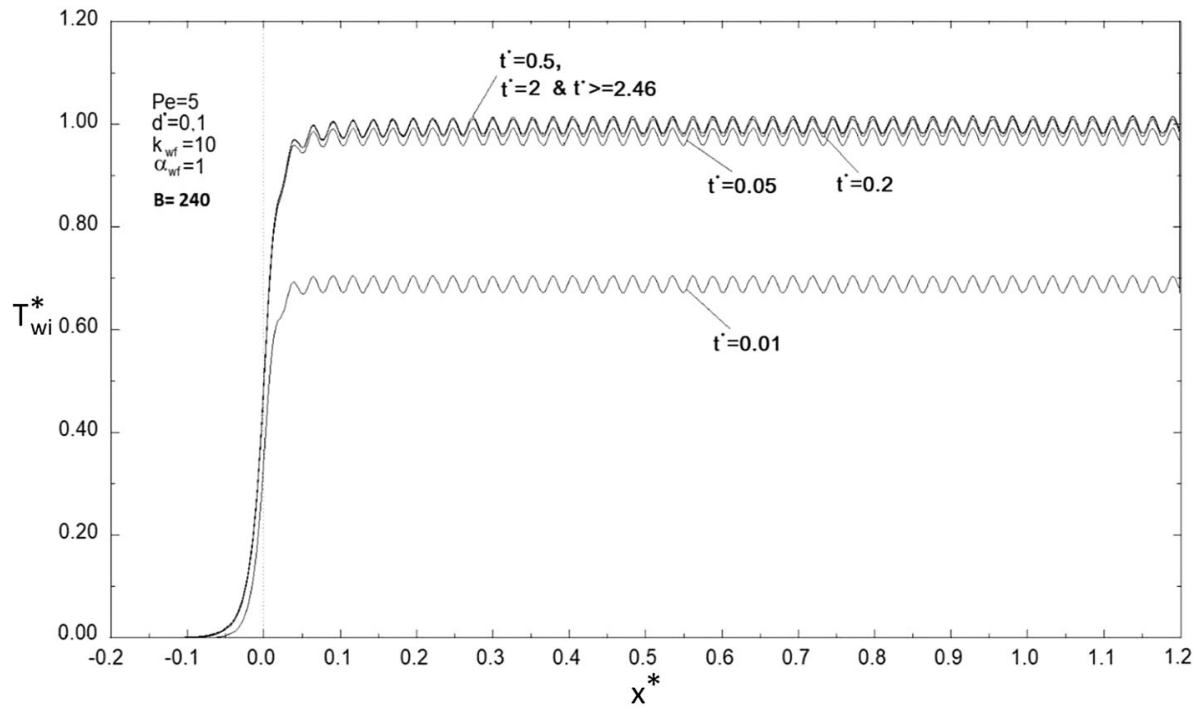

Figure 11. Transient axial distribution of interface temperature $(B=240)$.

the upstream region is observed to be increasing up to a certain level of frequency $B$ and then becoming almost constant. Because temperatures in radial direction tend like a constant temperature curve for higher frequencies (periodicity is removed or very small). This can be easily observed if figures 3 and 4 are compared to upcoming figures 12 and 13.

Examples of interface and fluid bulk temperature distributions are given for B $=90$ and B = 240 in figures 10-13. It is seen that interface temperatures are higher than the bulk temperatures during the initial phases of transient, except the axial positions in the far upstream region for higher values of $B$. The heat transferred backwards via axial conduction through the wall is lost partly from the outer surface since the outer surface temperature of the upstream region is held constant at $T_{O}$. Therefore, it can be said that heat diffuses further towards upstream due to the axial conduction in fluid side. For the same reason, temperatures are higher in the fluid side than in the wall side in the far upstream and heat is transferred from fluid to wall. This explains the negative interfacial heat flux realized in these locations. The amount of heat flux in the upstream region increases with time.

In the downstream region, negative interfacial heat flux is also seen at the beginning of the heating section up to $B=90$. For greater values of $B$ than 90 rapid wall 


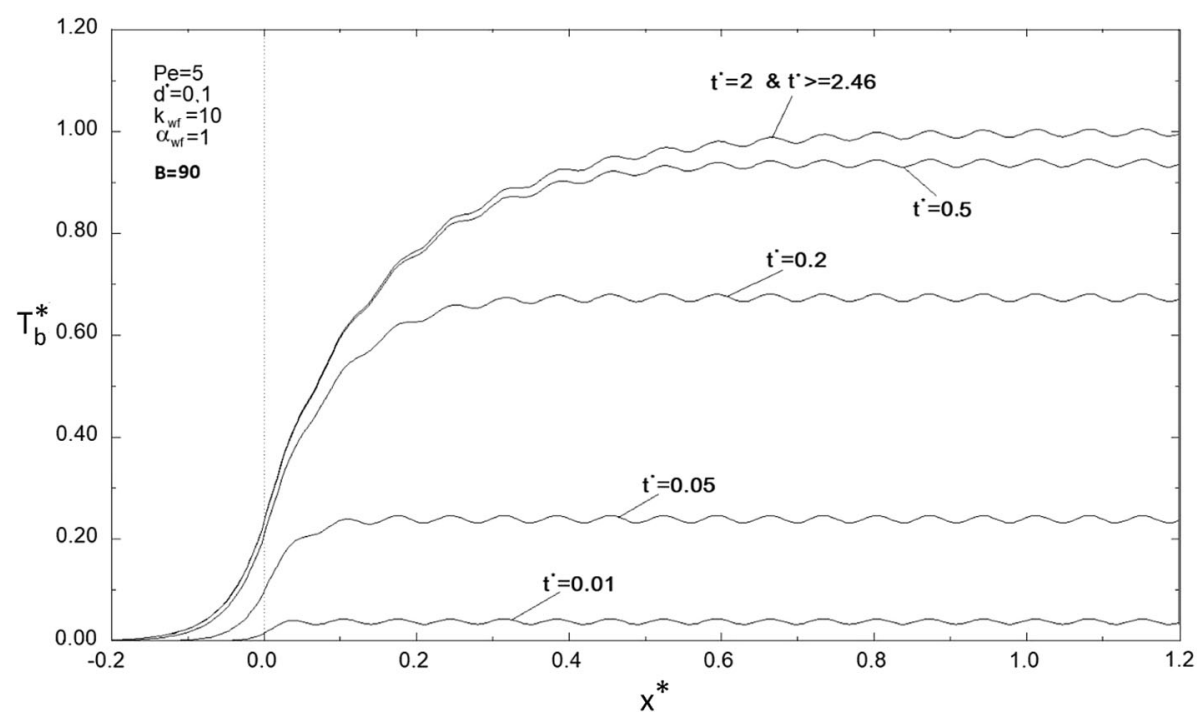

Figure 12. Transient axial distribution of bulk fluid temperature $(B=90)$.

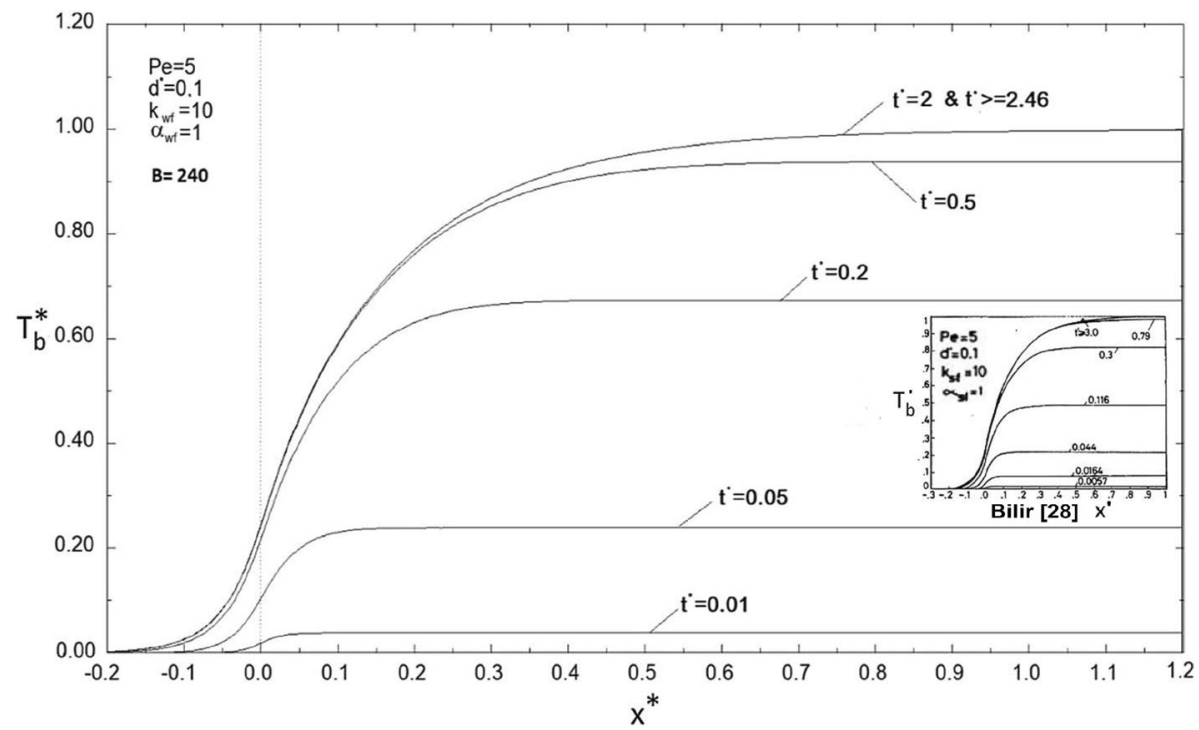

Figure 13. Transient axial distribution of bulk fluid temperature $(B=240)$.

conduction causes interface temperature to rise faster than the fluid temperature and interfacial heat flux to have a maximum by an increase. However, after a certain axial distance, the fluid temperature rises by the increasing effect of convection and heat flux values begin to decrease. This maximum value and also the amplitude decrease as the frequency increases. Hence, the development of the curves becomes more significant as frequency increases and the thermal entry length and the fully developed region is more evident. The flow develops thermally after a certain number of periods and the thermal entry length is shorter for frequency values up to $B=90$ and then becomes constant.

The period length of the outer surface temperature for values of $B$ greater than 600 becomes too short and the system inertia does not respond to this change. Then the amplitude of periodical change in heat transfer characteristics vanishes completely and the results become similar to the results of the work [28] in which a sudden change in temperature as $\Delta T$ was applied in the downstream region.

Above a certain frequency value, flow tends like as if there would be constant surface boundary condition. It is 

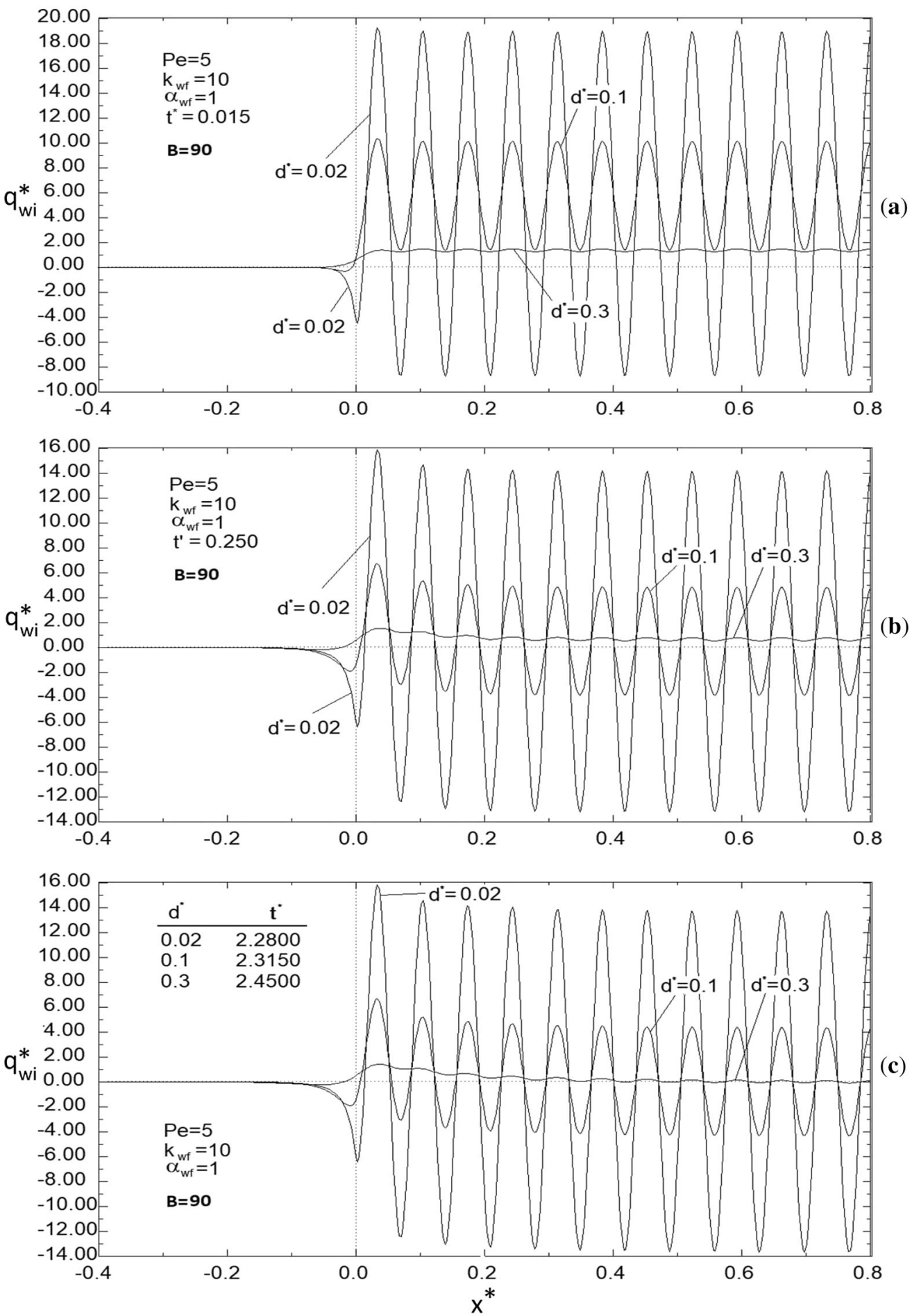

Figure 14. The effect of wall thickness ratio on interfacial heat flux.

clearly seen that wave amplitude is linear in figure 9 for $B=600$. A figure from the work that is done for constant surface temperature boundary condition of Bilir is inserted in figure 9 for comparison [28]. Similarly, it is seen that wave amplitude is linear in figure 13 for $\mathrm{B}=240$. Bulk temperature curves that are taken from reference [28] are also inserted into this figure. The similarity between figures can be clearly seen when they are compared. There are only small differences in the time steps.

Average values of the interfacial heat flux are zero, and for interface and bulk temperatures are 1.0 in the fully developed region for all frequency values. It is also seen 


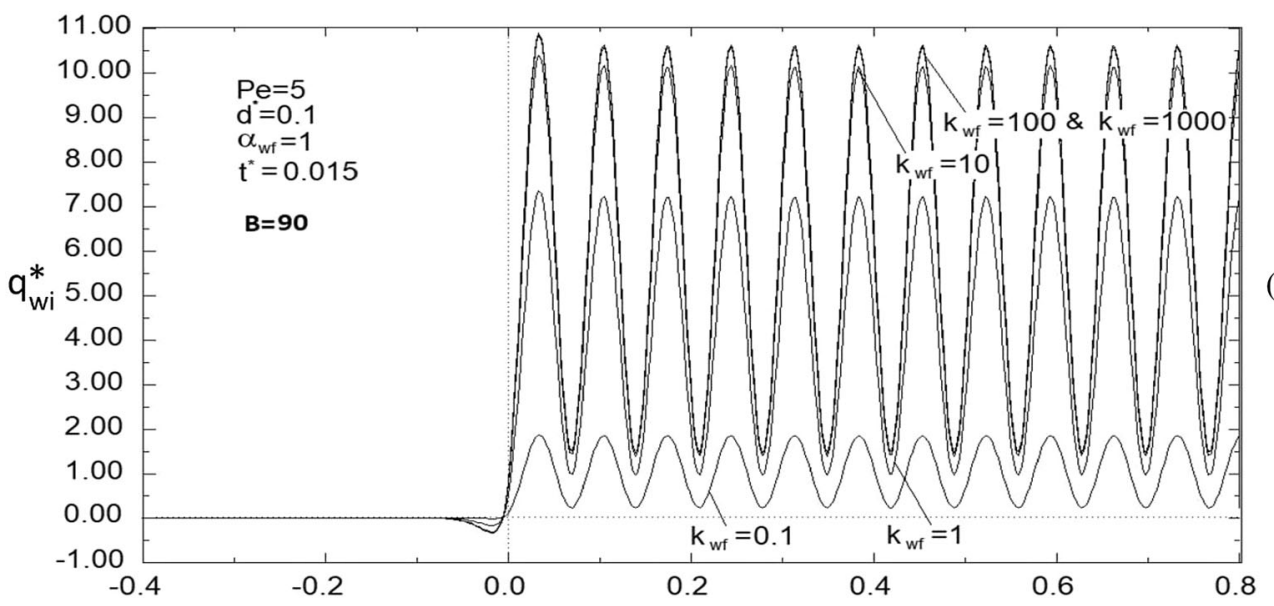

(a)

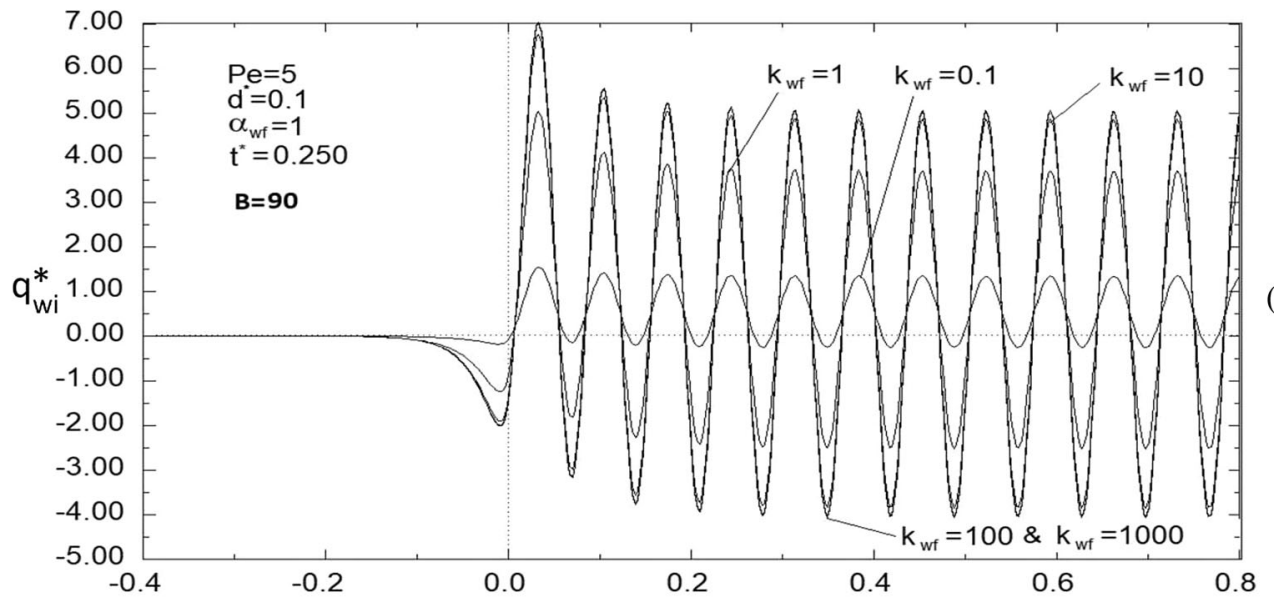

(b)

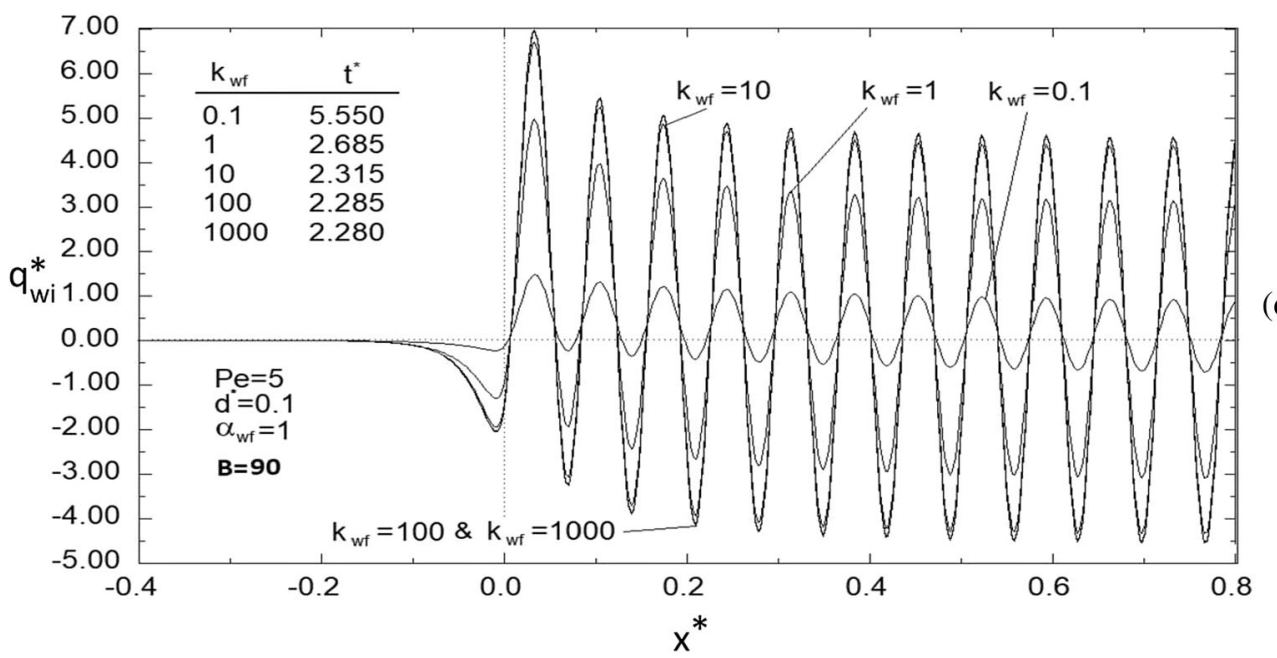

(c)

Figure 15. The effect of wall-to-fluid thermal conductivity ratio on interfacial heat flux.

that the frequency is affecting the thermal entry length but the time to reach to steady state is almost constant about $t^{*}=2.35$. Periodic oscillations become stable when the flow reaches steady state. According to this, average of the Cosine temperature curve becomes 0. In other words, negative heat fluxes (trough) and positive heat fluxes (peak) diminish each other. Therefore, $\Delta T$ temperature difference becomes 0 theoretically and interface heat flux becomes 0 .

The effects of the parameter values $\left(d^{*}, P e, k_{w f}\right.$ and $\left.\alpha_{w f}\right)$ on heat transfer characteristics are presented for $B=90$ since the effects of change in parameter values are not so evident for smaller $B$ values except $P e$. 


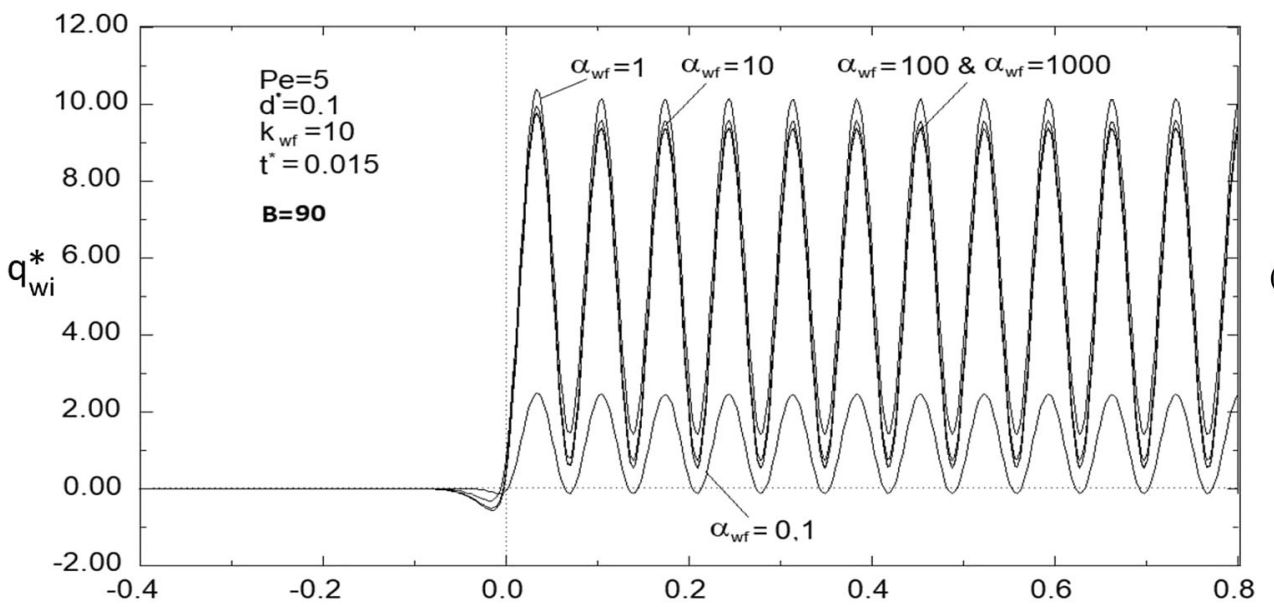

(a)

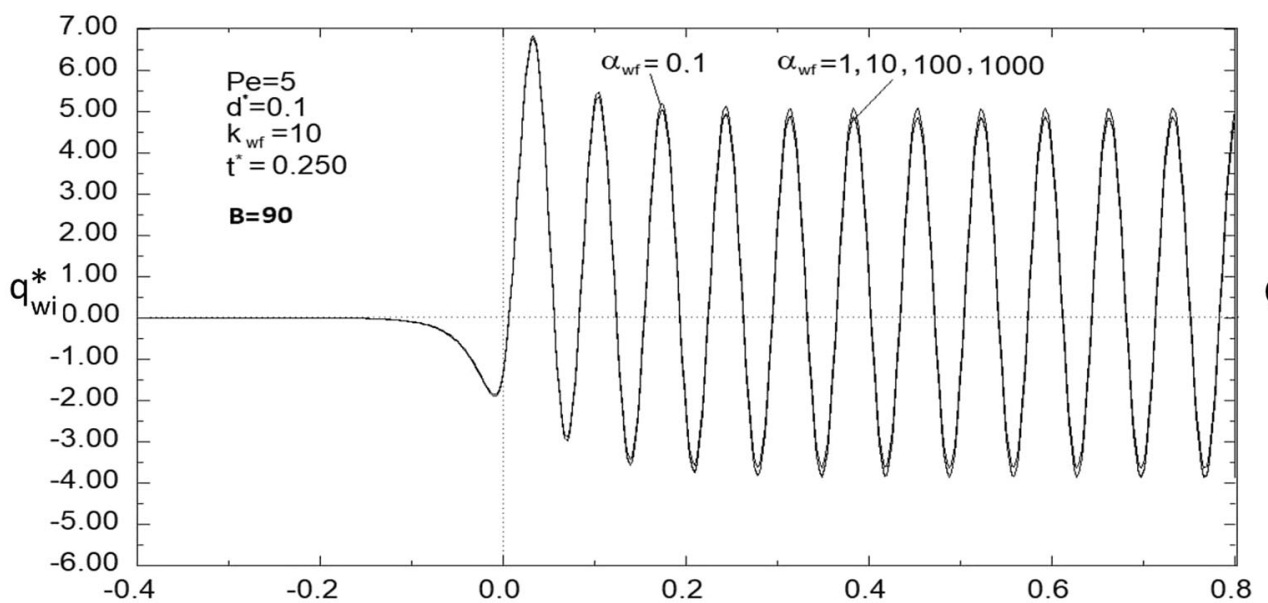

(b)

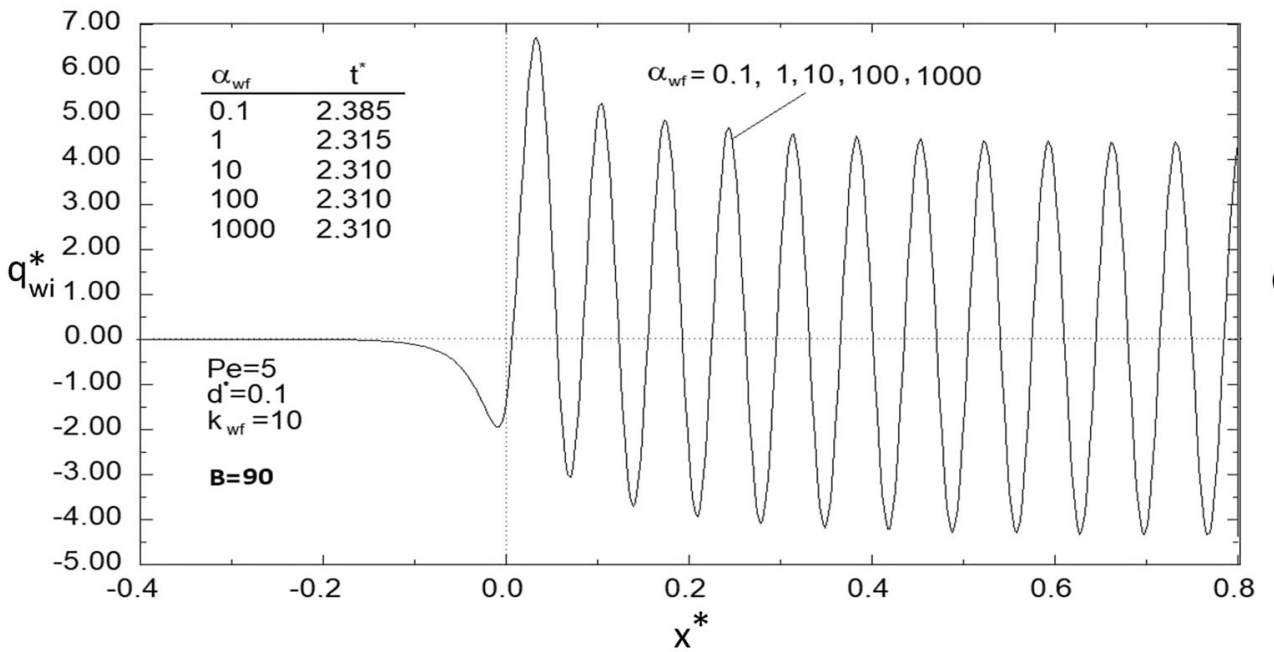

(c)

Figure 16. The effect of wall-to-fluid thermal diffusivity ratio on interfacial heat flux.

Figure 14 shows the effect of wall thickness ratio on interfacial heat flux. The figure is drawn for three different wall thickness ratios and at three different instants of time. The first of these time moments is at the very beginning of the transient, the second is at an intermediate time, and the third is in a steady state regime.
In thin walled pipes, due to low thermal resistance in the wall, the interface temperatures increase rapidly and therefore, higher interfacial heat flux values are seen in the downstream region. The amplitudes are also high since the thermal inertia is low for thin walls. It is also seen that, for fairly large wall thickness, i.e., $\mathrm{d}^{*}=0.3$, despite fluctuation heat flux values are usually positive in the thermal entrance 


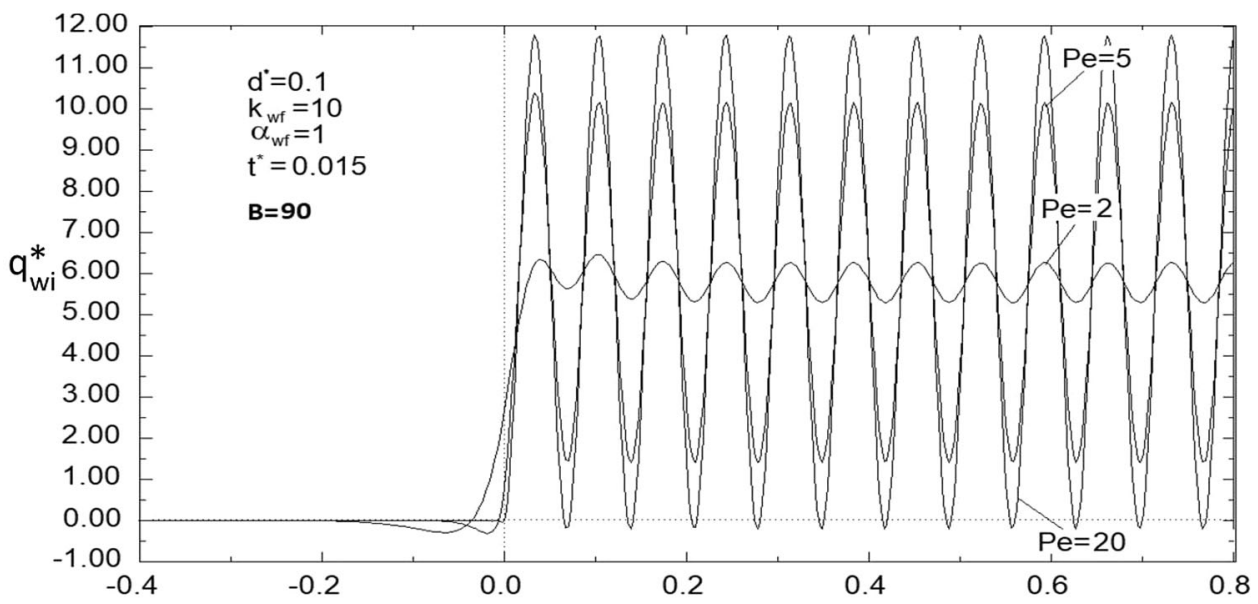

(a)

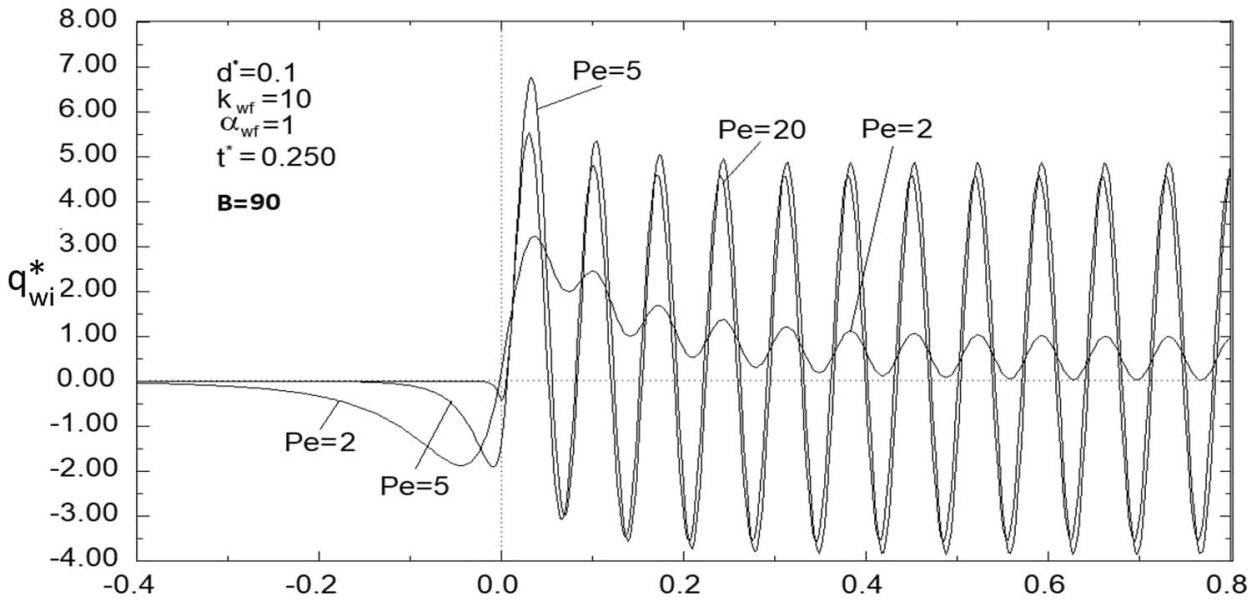

(b)

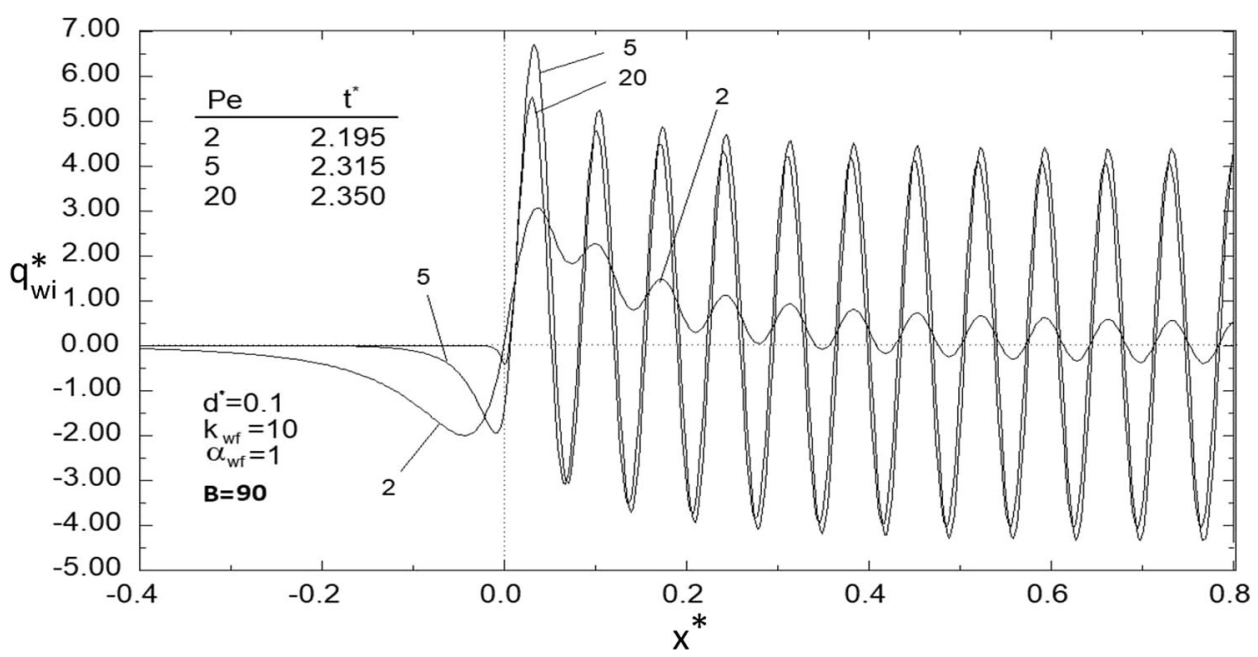

(c)

Figure 17. The effect of Peclet number on interfacial heat flux.

region and in most of the transient period. In the upstream region, on the other hand, heat transferred backwards due to axial wall conduction is partly lost from the outer wall surface and so inner wall temperatures are low than the fluid temperatures in thin walled pipes. This causes also higher negative interfacial heat flux values. These negative heat fluxes continue up to some distances in the heated downstream region for thin walls. The time to reach to steady state is increasing with increased wall thickness but the length of thermal development is not affected from the thickness ratio.

In figure 15, axial distributions of interfacial heat flux values are given for five different wall-to-fluid thermal conductivity ratios with other parameters are being held 
constant at the average values. Here, the results are also shown for three different instants of time. Because of rapid wall conduction higher heat flux values and higher amplitudes are seen for increased $\mathrm{k}_{\mathrm{wf}}$ values. At early transient the heat flux values are usually positive. Negative heat flux values shown in the upstream region are also high for high $\mathrm{k}_{\mathrm{wf}}$. The time to reach to steady state is decreasing with increased $\mathrm{k}_{\mathrm{wf}}$. The effect of wall-to-fluid thermal conductivity ratio is decreasing with its increased value and is said to vanish for $\mathrm{k}_{\mathrm{wf}}>100$.

The effect of wall-to-fluid thermal diffusivity ratio on interfacial heat flux is shown in figure 16. The curves are drawn for five different $\alpha_{\mathrm{wf}}$. Heat flux values and amplitudes are high for high $\alpha_{\mathrm{wf}}$, since thermal inertia in the wall decreases with increasing $\alpha_{\mathrm{wf}}$. It is seen that the effect of this parameter is influenced especially at early periods of transient. The curves are coinciding at steady state as expected, irrespective of the value of this parameter. The time to reach to steady state does not change with $\alpha_{\text {wf }}$. The effect of wall-to-fluid thermal diffusivity ratio is also decreasing with high values and can be seen to disappear for $\alpha_{\mathrm{wf}}>10$.

Figure 17 is given to show the effect of Peclet number on interfacial heat flux. The curves are drawn for three different Peclet numbers, again with $\mathrm{B}=90$ and at three different instants of time. Among the parameters, Peclet number may be described as the most decisive one on heat transfer characteristics. Since fluid axial conduction is high for low Peclet number flows, the backward transfer of heat towards upstream is high and both the magnitude and the extend of negative heat flux in the upstream region is increasing with decreasing Peclet number. It is clearly shown that the preheating region is considerably increases in low Peclet number flows. Convection effect decreases with decreasing Peclet number and therefore interface temperatures and fluid bulk temperatures are closer to each other. This is reducing the average values and amplitudes in small Peclet number flows. Due to the same reason the thermal development length is increasing for low Peclet number flows. For Pe $>20$ the effect of this parameter is negligible.

\section{Conclusion}

Transient conjugate heat transfer for laminar flow in the thermal entrance region of a pipe is investigated with involving the effect of fluid axial conduction. Solution domain is prepared in such a way that infinite thick walled pipe is divided into two regions as upstream and downstream region. Outer surfaces of the upstream and downstream regions are isothermal. Then outer surface of downstream region suddenly changes to an axially periodic temperature. A numerical finite-difference solution is made and a parametric study is done to analyze the effects of five independent defining parameters of the problem namely; the wall thickness ratio, $\mathrm{d}^{*}$, wall-to fluid thermal conductivity ratio, $\mathrm{k}_{\mathrm{wf}}$, wall-to fluid thermal diffusivity ratio, $\alpha_{\mathrm{wf}}$, the Peclet number, Pe, and the dimensionless frequency of the periodic temperature variation, $\mathrm{B}$. The results obtained can be summarized as follows.

1. A substantial amount of heat is transferred towards upstream region due to axial conduction both in the wall and the fluid sides. This backward heat diffusing causes preheating of the fluid in the unheated upstream region prior to the heated downstream region. The amount of preheating and the length of penetration in the upstream region is increasing with time. On the other hand, this preheating effect is observed only for frequency values of $\mathrm{B}>6$.

2. The magnitude of backward heat transfer to the upstream region is observed to be increasing up to a certain level of frequency $B$ and then becoming almost constant. This can be easily observed if figures 3 and 4 are compared with figures 12 and 13 .

3. Heat transfer characteristics change periodically as is the change in the outer wall temperature. The amplitudes of change are strongly dependent on the parameter values and the frequency.

4. The effects of wall conjugation and fluid axial conduction is increasing with increasing $\mathrm{d}^{*}$ and with decreasing $\mathrm{k}_{\mathrm{wf}}, \alpha_{\mathrm{wf}}$ and Pe. Beyond certain values, the effects of these parameters and also of the frequency are negligible. The parameter values also affect the length of thermal development and the time to reach the steady state.

5. In the fully developed region and in steady state, the average of the value of interface temperature is 1.0 while it is slightly smaller for fluid bulk temperature. The average of the interfacial heat flux and therefore the net heat transfer from pipe wall to fluid is zero in the fully developed region and in steady state.

\section{List of symbols}

$a$ constant of discretization equation (Eq. 5)

$B$ dimensionless frequency

$c_{p} \quad$ specific heat at constant pressure, $(\mathrm{kJ} / \mathrm{kg} \cdot \mathrm{K})$

$d$ thickness of the pipe wall, (m)

$F \quad$ Factor

Fo Fourier number

Gz Graetz number

$h$ the distance between nodes (Eq. 9), (m)

$k$ thermal conductivity, $(\mathrm{W} / \mathrm{m} \cdot \mathrm{K})$

$n$ total number of the nodes

$p \quad$ order of computational method

$P e \quad$ Peclet number

$q$ heat flux, $\left(\mathrm{W} / \mathrm{m}^{2} \cdot \mathrm{K}\right)$

$r$ radial coordinate, ratio of the distance between nodes or grid refinement ratio (Eq. 9) 
Re Reynolds number

$t$ time, (s)

$T$ temperature, (K)

$T_{o} \quad$ initial temperature of the system, $(\mathrm{K})$

$u$ axial velocity, $(\mathrm{m} / \mathrm{s})$

$x$ axial coordinate, $(\mathrm{m})$

\section{Greek symbols}

$\alpha$ thermal diffusivity, $\left(\mathrm{m}^{2} / \mathrm{s}\right)$

$\beta \quad$ frequency, $(\mathrm{Hz})$

$\delta r \quad$ radial position difference, $(\mathrm{m})$

$\delta x \quad$ axial position difference, $(\mathrm{m})$

$\Delta r \quad$ radial step size, $(\mathrm{m})$

$\Delta t$ time step increment, (s)

$\Delta T$ amplitude of periodic temperature variation, $(\mathrm{K})$

$\Delta x \quad$ axial step size, $(\mathrm{m})$

$\varepsilon \quad$ relative error

$\varphi$ global variable for the RMS calculation

$\rho$ density, $\left(\mathrm{kg} / \mathrm{m}^{3}\right)$

\section{Subscripts}

$b \quad$ bulk

c coarse

$f \quad$ fluid, fine

$i \quad$ inner wall

$\mathrm{i}, \mathrm{j} \quad$ at nodal point $i, j$

$\mathrm{m}$ mean

$\max$ maximum

o outer wall

$s \quad$ safety

$w \quad$ wall

$w f \quad$ ratio of wall to fluid

$w i \quad$ wall to fluid interface

\section{Superscripts}

* dimensionless quantity

$o$ at previous time step

\section{References}

[1] Wijeysundera N E 1986 Laminar forced convection in circular and flat ducts with wall axial conduction and external convection. Int. J. Heat Mass Transf. 29: 797-807 https://doi. org/10.1016/0017-9310(86)90131-6

[2] Bilir S 1995 Laminar flow heat transfer in pipes including two dimensional wall and fluid axial conduction. Int. J. Heat Mass Transf. 38: 1619-1625 https://doi.org/10.1016/00179310(94)00269-2

[3] Schutte D J, Rahman M M and Faghri A 1992 Transient conjugate heat transfer in a thick walled pipe with developing laminar flow. Numer. Heat Transf. Part A Appl. 21: 163-186 https://doi.org/10.1080/10407789108944871

[4] Vick B, Ozisik M N and Ullrich D F 1983 Effects of axial conduction in laminar tube flow with convective boundaries. J. Frankl. Inst. 316: 159-173 https://doi.org/10.1016/00160032(83)90083-2
[5] Lee S L and Hwang G J 1981 Finite element solution of low Peclet number fluid flow in round pipe with the Cauchy boundary condition. Can. J. Chem. Eng. 59: 760-765 https:// doi.org/10.1002/cjce.5450590617

[6] Ates A 1998 Transient conjugated heat transfer in thick walled pipes with convective boundary conditions. Ph.D. Thesis. Selcuk University, Konya, Turkey

[7] Darici S 2004 Transient conjugated heat transfer in simultaneously developing laminar flow in thick walled pipes. Ph.D. Thesis. Selcuk University, Konya, Turkey

[8] Hsu C-J 1965 Heat transfer in a round tube with sinusoidal wall heat flux distribution. AIChE J. 11: 690-695. https://doi. org/10.1002/aic.690110423

[9] Patankar S V, Liu C H and Sparrow E M 1978 The periodic thermally developed regime in ducts with streamwise periodic wall temperature or heat flux. Int. J. Heat Mass Transf. 21: 557-565. https://doi.org/10.1016/0017-9310(78)90052-2

[10] Li W and Kakac S 1991 Unsteady thermal entrance heat transfer in laminar flow with a periodic variation of inlet temperature. Int. J. Heat Mass Transf. 34(10): 2581-2592. https://doi.org/10.1016/0017-9310(91)90098-Y

[11] Quaresma J N N and Cotta R M 1994 Exact solutions for thermally developing tube flow with variable wall heat flux. Int. Commun. Heat Mass Transf. 21(5): 729-742. https://doi. org/10.1016/0735-1933(94)90074-4

[12] Yan W-M 1993 Transient conjugated heat transfer in channel flows with convection from the ambient. Int. J. Heat Mass Transf. 36: 1295-1301. https://doi.org/10.1016/S00179310(05)80098-5

[13] Myong H K, Kasagi N and Hirata M 1990 Numerical prediction of turbulent pipe flow heat transfer for various Prandtl number fluids with the improved $\mathrm{k}-\varepsilon$ turbulence model. JSME Znt. JI. 32: 613-622. https://doi.org/10.1299/ jsmeb1988.32.4_613

[14] Barletta A and Zanchini E 1995 Laminar forced convection with sinusoidal wall heat flux distribution: axially periodic regime. Heat Mass Transf. 31: 41-48. https://doi.org/10. 1007/BF02537420

[15] Barletta A and Rossi di Schio E 1999 Effects of viscous dissipation on laminar forced convection with axially periodic wall heat flux. Heat Mass Transf. 35: 9-16. https://doi. org/10.1007/s002310050292

[16] Barletta A and Rossi di Schio E 2000 Periodic forced convection with axial heat conduction in a circular duct. Int. J. Heat Mass Transf. 43: 2949-2960. https://doi.org/10.1016/ S0017-9310(99)00360-9

[17] Barletta A, Rossi di Schio E, Comini G and D'Agaro P 2009 Wall coupling effect in channel forced convection with streamwise periodic boundary heat flux variation. Int. J. Therm. Sci. 48: 699-707. https://doi.org/10.1016/j.ijther malsci.2008.06.003

[18] Zniber K, Oubarra A and Lahjomri J 2005 Analytical solution to the problem of heat transfer in an MHD flow inside a channel with prescribed sinusoidal wall heat flux. Energy Convers. Manag. 46: 1147-1163. https://doi.org/10.1016/j. enconman.2004.06.023

[19] Barletta A and Magyari E 2007 Forced convection with viscous dissipation in the thermal entrance region of a circular duct with prescribed wall heat flux. Int. J. Heat Mass Transf. 50: 26-35. https://doi.org/10.1016/j.ijheatmas stransfer.2006.06.036 
[20] Barletta A, Rossi di Schio E, Comini G and D'Agaro P 2008 Conjugate forced convection heat transfer in a plane channel: Longitudinally periodic regime. Int. J. Therm. Sci. 47: 43-51. https://doi.org/10.1016/j.ijthermalsci.2007.01.013

[21] Conti A, Lorenzini G and Jaluria Y 2012 Transient conjugate heat transfer in straight microchannels. Int. J. Heat Mass Transf. 55: 7532-7543. https://doi.org/10.1016/j.ijheatmas stransfer.2012.07.046

[22] Altun A H, Bilir S and Ates A 2016 Transient conjugated heat transfer in thermally developing laminar flow in thick walled pipes and minipipes with time periodically varying wall temperature boundary condition. Int. J. Heat Mass Transf. 92: 643-657. https://doi.org/10.1016/j.ijheatmas stransfer.2015.09.011

[23] Aydin O, Avci M, Bali T and Arıcı M E 2014 Conjugate heat transfer in a duct with an axially varying heat flux. Int. J. Heat Mass Transf. 76: 385-392. https://doi.org/10.1016/j. ijheatmasstransfer.2014.04.062

[24] Aydın O and Avcı M 2015 Laminar forced convective slip flow in a microduct with a sinusoidally varying heat flux in axial direction. Int. J. Heat Mass Transf. 89: 606-612. https://doi.org/10.1016/j.ijheatmasstransfer.2015.05.056

[25] Zhu X W, Fu Y H and Zhao J Q 2016 A novel wavy-tape insert configuration for pipe heat transfer augmentation. Energy Convers. Manag. 127: 140-148. https://doi.org/10. 1016/j.enconman.2016.09.006

[26] Bilir S 1992 Numerical solution of Graetz problem with axial conduction. Numer. Heat Transf. Part A Appl. 21: 493-500. https://doi.org/10.1080/10407789208944889

[27] Patankar S V 1980 Chapter 4 Numerical heat transfer and fluid flow. In: W J Minkowycz and A M Sparrow (eds),
Newyork: Hemisphere Publishing Corporation, McGraw-Hill Book Company, pp. 44-47

[28] Bilir S 2002 Transient conjugated heat transfer in pipes involving two-dimensional wall and axial fluid conduction. Int. J. Heat Mass Transf. 45: 1781-1788. https://doi.org/10. 1016/S0017-9310(01)00270-8

[29] Bilir S and Ates A 2003 Transient conjugated heat transfer in thick walled pipes with convective boundary conditions. Int J. Heat Mass Transf. 46(14): 2701-2709. https://doi.org/10. 1016/S0017-9310(03)00032-2

[30] Ates A, Darici S and Bilir S 2010 Unsteady conjugated heat transfer in thick walled pipes involving two-dimensional wall and axial fluid conduction with uniform heat flux boundary condition. Int. J. Heat Mass Transf. 53(23-24): 5058-5064. https://doi.org/10.1016/j.ijheatmasstransfer.2010.07.059

[31] Darici S, Bilir S and Ates A 2015 Transient conjugated heat transfer for simultaneously developing laminar flow in thick walled pipes and minipipes. Int. J. Heat Mass Transf. 84: 1040-1048. http://dx.doi.org/10.1016/j.ijheatmasstransfer. 2014.12.049

[32] Atmaca U, Bilir S and Ates A 2017 Effects of wall conjugation and fluid axial conduction in circumferentially partly heated pipes and minipipes. Heat Transf. Res. 48(16): 1433-1458. https://doi.org/10.1615/heattransres.2017017830

[33] Roache P J 1994 Perspective: A method for uniform reporting of grid refinement studies. J. Fluids Eng. 116(3): 405-413. https://doi.org/10.1115/1.2910291

[34] Faghri M and Sparrow E M 1980 Forced convection in a horizontal pipe subjected to nonlinear external natural convection and to external radiation. Int. J. Heat Mass Transf. 23(6): 861-872. https://doi.org/10.1016/0017-9310(80)90041-1 